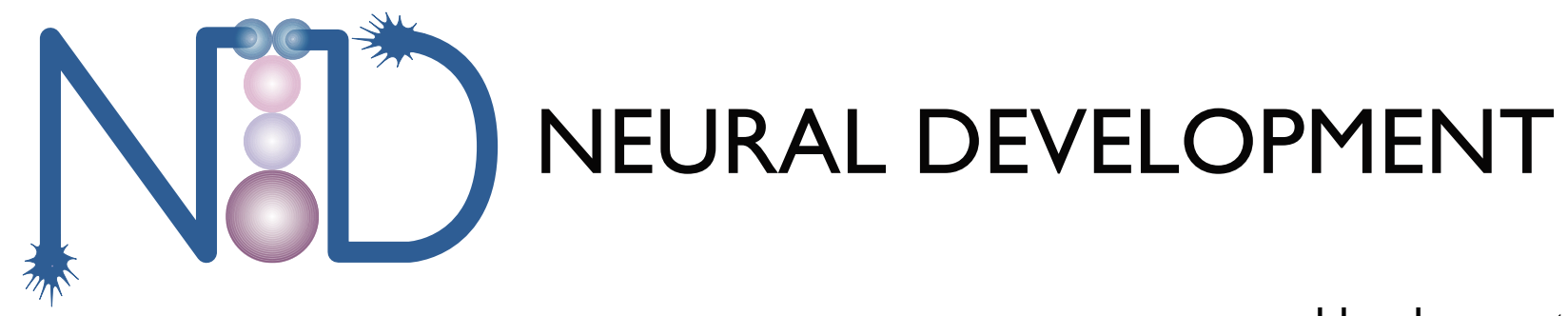

www.neuraldevelopment.com

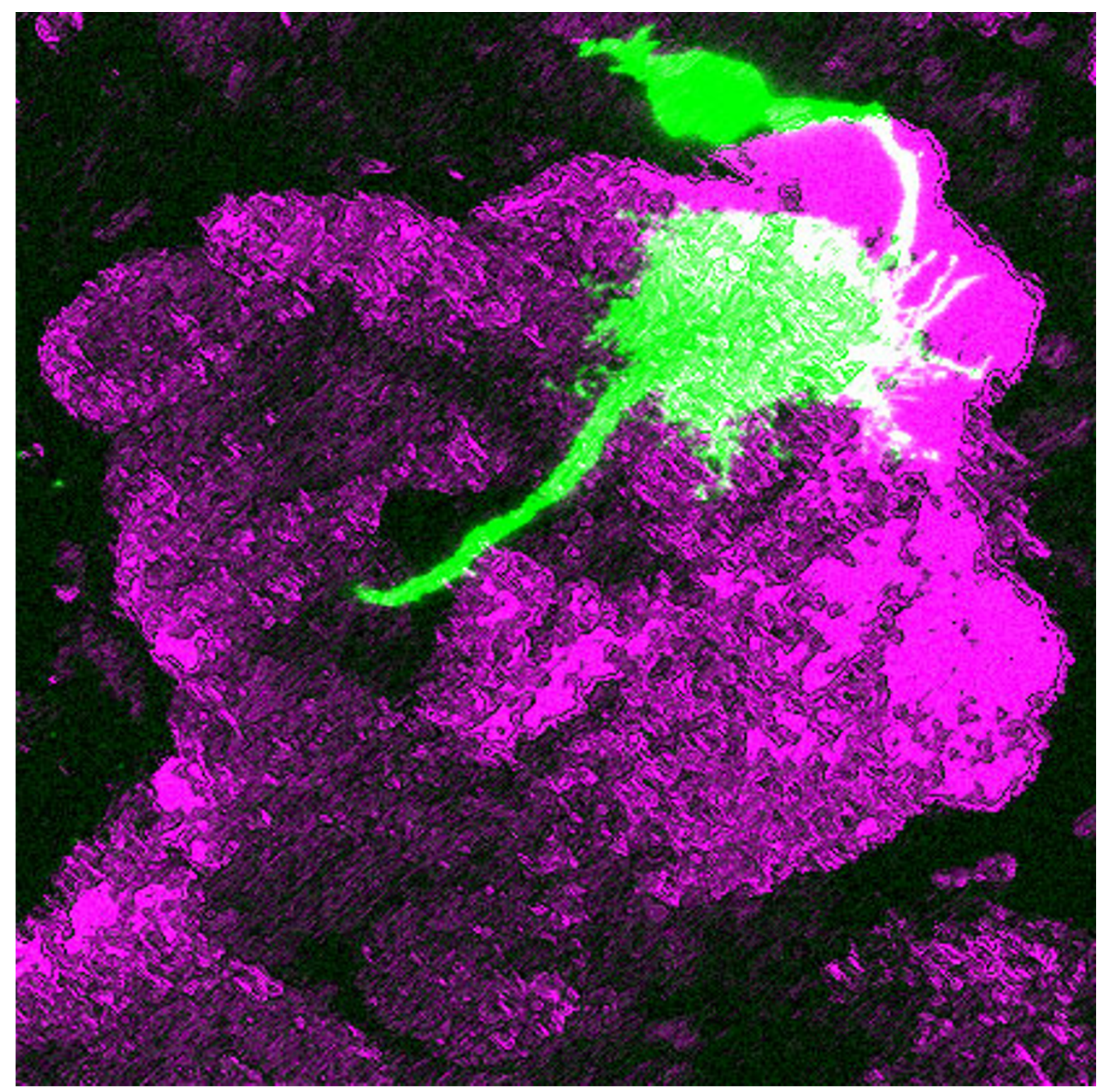

\title{
Lola regulates Drosophila olfactory projection neuron identity and targeting specificity
}

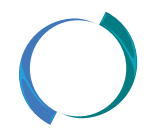

Maria Lynn Spletter et al. 


\title{
Lola regulates Drosophila olfactory projection neuron identity and
} targeting specificity

\author{
Maria Lynn Spletter ${ }^{1}$, Jian Liu ${ }^{2,3}$, Justin Liu ${ }^{1}$, Helen Su ${ }^{1,4}$, Edward Giniger ${ }^{5}$, \\ Takaki Komiyama ${ }^{1,4}$, Stephen Quake ${ }^{2}$ and Liqun Luo*1
}

\begin{abstract}
Address: ${ }^{1}$ Howard Hughes Medical Institute, Department of Biological Sciences, Stanford University, Stanford, California 94305, USA, ${ }^{2}$ Howard Hughes Medical Institute, Department of Bioengineering, Stanford University, Stanford, California 94305, USA, ${ }^{3}$ Department of Biomedical Engineering, Emory University, Atlanta, Georgia 30322, USA, Janelia Farm Research Campus, Howard Hughes Medical Institute, Ashburn, VA 20147, USA and ${ }^{5}$ National Institute of Neurological Disorders and Stroke, National Institutes of Health, Bethesda, MD 20892, USA

Email: Maria Lynn Spletter - spletter@stanford.edu; Jian Liu - jliu44@emory.edu; Justin Liu - jliu85@stanford.edu; Helen Su - suh@janelia.hhmi.org; Edward Giniger - ginigere@ninds.nih.gov; Takaki Komiyama - komiyamat@janelia.hhmi.org; Stephen Quake - quake@stanford.edu; Liqun Luo* - lluo@stanford.edu

* Corresponding author
\end{abstract}

Published: 16 July 2007

Neural Development 2007, 2:14 doi:10.1186/1749-8/04-2-14
Received: 4 April 2007

Accepted: 16 July 2007

This article is available from: http://www.neuraldevelopment.com/content/2/1/14

(c) 2007 Spletter et al.; licensee BioMed Central Ltd.

This is an open access article distributed under the terms of the Creative Commons Attribution License http://creativecommons.org/licenses/by/2.0, which permits unrestricted use, distribution, and reproduction in any medium, provided the original work is properly cited.

\begin{abstract}
Background: Precise connections of neural circuits can be specified by genetic programming. In the Drosophila olfactory system, projection neurons (PNs) send dendrites to single glomeruli in the antenna lobe $(A L)$ based upon lineage and birth order and send axons with stereotyped terminations to higher olfactory centers. These decisions are likely specified by a PN-intrinsic transcriptional code that regulates the expression of cell-surface molecules to instruct wiring specificity.

Results: We find that the loss of longitudinals lacking (lola), which encodes a BTB-Zn-finger transcription factor with 20 predicted splice isoforms, results in wiring defects in both axons and dendrites of all lineages of PNs. RNA in situ hybridization and quantitative RT-PCR suggest that most if not all lola isoforms are expressed in all PNs, but different isoforms are expressed at widely varying levels. Overexpression of individual lola isoforms fails to rescue the lola null phenotypes and causes additional phenotypes. Loss of lola also results in ectopic expression of Gal4 drivers in multiple cell types and in the loss of transcription factor gene $\lim /$ expression in ventral PNs.

Conclusion: Our results indicate that lola is required for wiring of axons and dendrites of most PN classes, and suggest a need for its molecular diversity. Expression pattern changes of Gal4 drivers in lola $^{-1}$ clones imply that lola normally represses the expression of these regulatory elements in a subset of the cells surrounding the AL. We propose that Lola functions as a general transcription factor that regulates the expression of multiple genes ultimately controlling PN identity and wiring specificity.
\end{abstract}

\section{Background}

Nervous systems exhibit highly reproducible patterns of connectivity that are essential for their proper functions.
Axon pathfinding in many systems is heavily dependent upon genetically programmed expression of guidance factors and their receptors [1]. Recent studies have indicated 
that dendrite target selection and aspects of synapse specificity can also be precisely genetically programmed in flies [2] and vertebrates [3]. For example, wiring specificity in the adult Drosophila olfactory system is achieved during pupal development before the onset of olfactory receptor expression [4]. Olfactory receptor neurons (ORNs) project their axons to glomeruli in the antennal lobe $(\mathrm{AL})$, where they synapse with the dendrites of projection neurons (PNs) (Figure 1a; reviewed in $[5,6]$ ). PNs target their dendrites to single glomeruli and send their axons to stereotypic locations in the mushroom body (MB) and lateral horn (LH) according to their glomerular class [7-9]. Most PNs are derived from three neuroblast lineages, anterodorsal (adPNs), lateral (lPNs) and ventral (vPNs). adPNs and IPNs innervate intercalating but non-overlapping sets of glomeruli, suggesting lineage-specific control of targeting. Additionally, adPNs are specified by birth order, suggesting that instructive information within a lineage determines wiring patterns [2]. Indeed, PN dendritic patterning precedes ORN axon patterning: by the time pioneering ORN axons arrive at the developing $\mathrm{AL}, \mathrm{PN}$ dendrites have already formed a coarse map by virtue of their specific dendritic targeting [4].

Several cell-surface proteins, including Sema-1a, Dscam and $\mathrm{N}$-Cadherin, have been shown to play different roles in PN dendritic development. These studies suggest a model in which PN dendrites first target to a rough region of the AL based on molecular gradients and then are further refined by dendro-dendritic and dendro-axonal interactions [10-12]. The expression of these and additional cell-surface proteins are likely controlled by a transcriptional code that acts to uniquely specify the wiring aptitude of individual PNs[13,14]. Studies of several transcription factors (TFs) support the existence of a transcriptional hierarchy in PNs. Some factors, such as the LIM cofactor Chip, appear to affect wiring in all PN classes [14]. Other TFs show lineage specific restriction in expression and regulatory effects. For example, the LIM-homeodomain TF Islet is required for proper targeting of a subset of adPNs and IPNs, while the homeodomain TF Cut is required in only a subset of IPNs and all vPNs [14]. As another example, POU-domain TFs Acj6 and Drifter have restricted expression patterns in adPN and IPN lineages, respectively, and control wiring specificity in their respective lineages [13]. A recently identified BTB-Zn-finger TF, Chinmo, regulates birth order-dependent wiring of adPNs. Loss of chinmo results in adPNs born in early larval life acquiring the targeting specificity of late-born PNs within the same lineage [15]. There are also TFs that appear to affect targeting of a single PN type. For example, the LIM-homeodomain TF Lim1 is necessary for proper targeting of a single vPN to the DA1 glomerulus, and is regulated by Cut. The Zn-finger TF Squeeze appears to be necessary for the innervation of a single IPN glomerulus,
DM5 [14]. All these studies support a model where the targeting specificity of a particular PN is regulated by a unique complement of TFs, and additional members of the TF code remain to be identified.

The gene longitudinals lacking (lola) encodes a molecularly diverse BTB-Zn-finger TF with at least 20 unique protein isoforms (Figure 1b). Each isoform is formed by combining a set of common BTB-containing amino-terminal exons to unique Zn-finger-containing carboxy-terminal exons via trans- and/or cis-pre-mRNA splicing [16-18]. The BTB (Broad complex, Tramtrack, Bric à brac) domain, also referred to as the POZ (poxvirus and $\mathrm{Zn}$-finger) domain, is a common domain likely involved in protein-protein interactions [19]. Most lola isoforms have one or more unique $\mathrm{Zn}$-fingers of either the $\mathrm{C}_{2} \mathrm{H}_{2}$ type that binds DNA, or the unusual $\mathrm{C}_{2} \mathrm{HC}$ class that binds nucleosomes, nonhistone proteins, RNA and DNA [20,21]. At least some Lola isoforms bind DNA directly [22]. Interestingly, three Lola isoforms lack $\mathrm{Zn}$-fingers and theoretically could be involved in heteromeric regulatory interactions with other Lola isoforms, as Lola was found to bind itself in yeasttwo-hybrid interactions and co-immunoprecipitation experiments $[21,23]$. Lola also likely interacts with other proteins such as chromosomal kinase JIL-1 [21].

Lola was initially identified as a factor that regulates axon guidance in the embryonic central nervous system longitudinal tracks, and is reported to function in a wide array of other cellular processes. lola mutants exhibit defects in the extension of embryonic longitudinal axons and midline crossing, orientation of lateral chordotonal neurons, and $\mathrm{ISN}_{\mathrm{b}}$ axon growth and elaboration [24,25]. Mutation of Lola isoforms $\mathrm{K}$ or $\mathrm{L}$ is sufficient to inactivate a specific subset of lola functions in ISN $_{\mathrm{b}}$ neurons, suggesting that different Lola isoforms may have unique functions [16]. lola was recently identified to disrupt ORN axonal innervation of the AL in an overexpression screen [26]. lola may exert its effect through transcriptional regulation of cellsurface molecules, and has been reported to genetically interact with Notch, slit, and robo $[27,28]$. lola may have a more general regulatory role as a polycomb group (PcG) factor affecting cell proliferation via the Notch pathway and regulating wing development through a genetic interaction with cut [29].

In this study, we show that lola plays an essential role in PN identity and wiring specificity. lola appears to be a general factor that affects wiring of both axons and dendrites in all three lineages of PNs. Overexpression of UAS-lola T and UAS-lola $L$, but not UAS-lola $A$, results in wiring defects. Additionally, expression of single lola isoforms is insufficient to rescue the lola null phenotype and often causes additional defects specific to the isoforms expressed, suggesting the importance of Lola molecular 

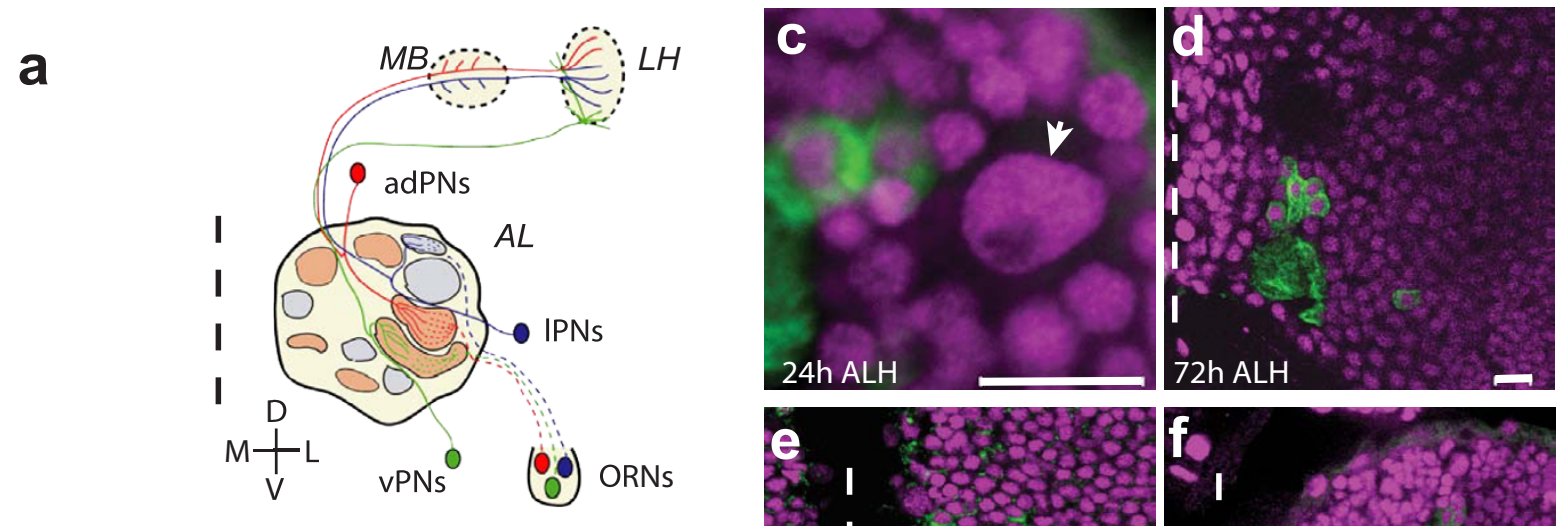

b
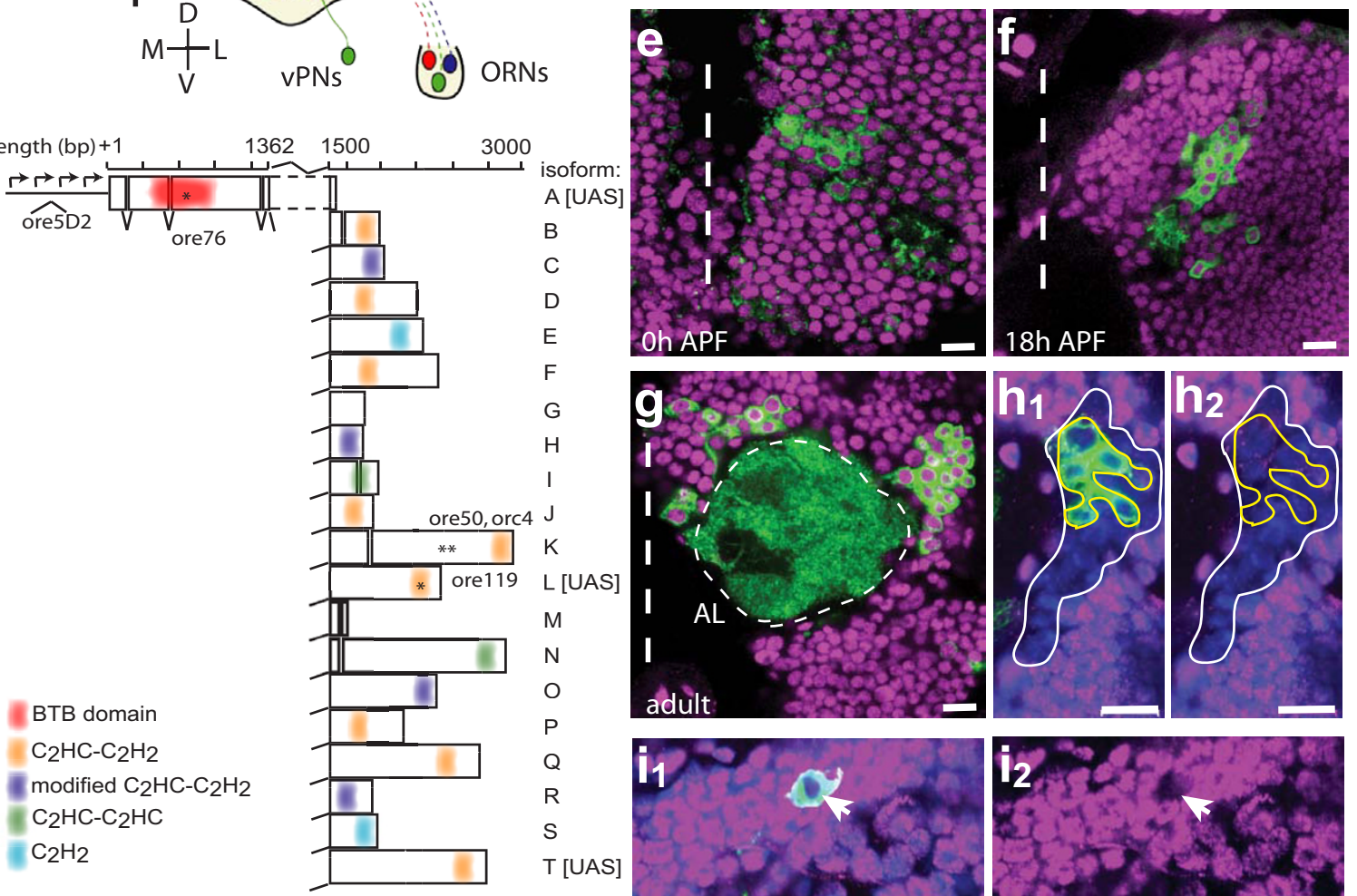

G
[UAS]
$N$
N
R
[UAS]
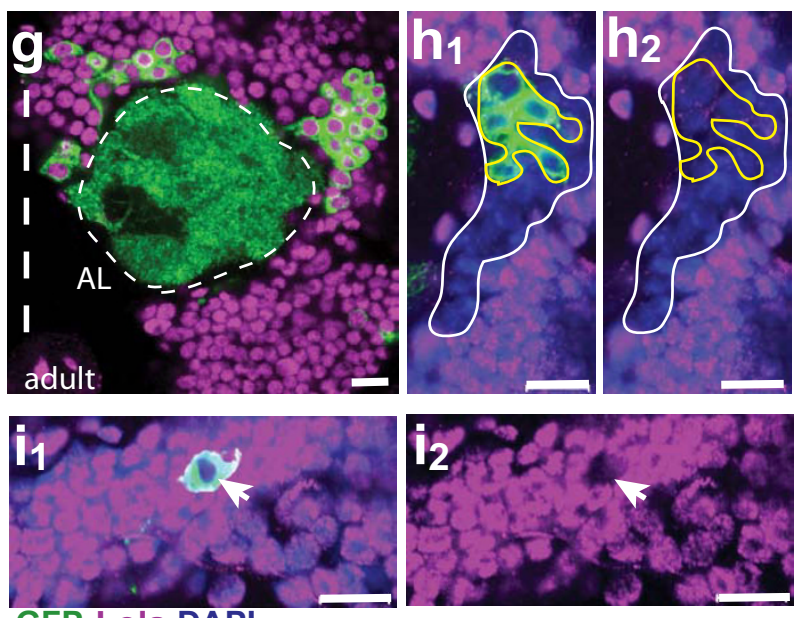

Figure I

The Drosophila olfactory system, the Iola gene, and Lola expression. (a) Schematic representation of the Drosophila antennal lobe. Olfactory receptor neuron (ORN) axons project to stereotyped glomeruli in the antennal lobe (AL). The anterodorsal (ad), lateral (I) and ventral (v) lineages of Gal4-GHI46 positive PNs send dendrites to specific glomeruli in the AL and axons to specific regions in the mushroom body (MB) calyx and lateral horn (LH). (b) Schematic representation of the lola gene. lola is a complex genetic locus consisting of at least 20 isoforms generated by both cis- and trans-splicing of an amino-terminal BTB domain-containing common region to unique carboxy-terminal exons, most of which contain Zn fingers. Individual isoforms are labeled in accordance with previous nomenclature [16]. Mutations are marked by asterisks and isoforms with UAS transgenes are listed. (c-g) Time course of Lola expression using an antibody generated against the common region (amino acids 19-467). Lola is expressed in all neurons adjacent to the AL at all stages of development, shown at $24 \mathrm{~h}$ after larval hatching $(\mathrm{ALH}), 72 \mathrm{~h} \mathrm{ALH}, 0 \mathrm{~h}$ after puparium formation (APF), $18 \mathrm{~h}$ APF and adult. Lola is also expressed in the neuroblast (arrow in c). In this and all subsequent figures, non-overlapping fluoresence channels are pseudocolored for ease of viewing: anti-CD8::GFP in green, anti-Lola in magenta. Dashed vertical line marks the midline. Antenna lobe $(\mathrm{AL})$ outlined with thin dashed line in $(\mathrm{g})$. $(h, i)$ Specificity of anti-Lola antibody. Lateral lola-l- (ore76) MARCM clone stained with anti-pan Lola. In (h), the white outline denotes entire MARCM clone determined by loss of Lola staining. The yellow outline denotes boundary of GHI46 positive cells based on GFP expression. Loss of Lola staining in GHI46 cells can be seen clearly in the magenta (Lola) only channel ( $\left.\mathrm{h}_{2}\right)$. In (i), a DLI single-cell lola-MARCM clone shows a loss of Lola staining in the magenta channel $\left(i_{2}\right)$. The arrow marks the same cell in $\left(i_{1}\right)$ and $\left(i_{2}\right)$. Scale $10 \mu \mathrm{m}$. Green, anti-CD8::GFP; magenta, anti-Lola; blue, DAPI. 
diversity in regulating PN wiring specificity. Indeed most lola isoforms are expressed in PNs but at different levels. Finally, consistent with previous findings of transcriptional regulation and potential PcG function, we find that lola likely regulates $\lim 1$ and several Gal4 enhancer trap lines in PNs. We suggest that lola regulates PN wiring through transcriptional regulation of downstream targets involved in defining neuronal identity and targeting specificity.

\section{Results and discussion}

We investigated the function of lola in wiring specificity of olfactory PNs by using the MARCM (mosaic analysis with a repressible cell marker) system [30]. PNs send dendrites to specific glomeruli in the $\mathrm{AL}[2]$ and axons to the $\mathrm{MB}$ and LH in highly stereotyped patterns [7-9] (Figure 1a), allowing us to examine lola function in both dendrites and axons.

\section{Lola is expressed in projection neurons and neuroblasts}

Using a specific antibody raised against the domain common to all Lola isoforms (Figure 1b), we found that Lola is expressed in all cells in the AL region at all stages of development from larva to adult (Figure 1c-g). These include expression in post-mitotic cells such as PNs, but also in neuroblasts, which we can identify by their size during larval development (Figure 1c). Antibody specificity was confirmed by loss of Lola staining in neuroblast and single-cell MARCM clones homozygous for a lola null allele (ore76, which introduces an early stop codon in the BTB domain of all Lola isoforms (Figure 1b), hereafter referred to as lola $\%$ ) in adult (Figure 1h,i) and in early pupa (data not shown). Note that Lola staining can be used to identify all mutant cells in a MARCM clone that are not necessarily labeled by UAS-mCD8::GFP because Lola is expressed ubiquitously throughout the brain, while Gal4 enhancer traps often have a more limited domain of expression (Figure $1 \mathrm{~h}$ ).

\section{lola mutant projection neurons have dendrite wiring defects}

Since Lola is expressed in PNs during AL development, and mutant clones effectively eliminate Lola protein during the period of dendritic targeting, we proceeded to analyze the phenotype of lola $/$ - PN MARCM clones. Using the Gal4-GH146 enhancer-trap line to label PNs, we observed wiring defects in all lineages of PN MARCM clones as well as anterodorsal single cell clones that normally target the DL1 glomerulus (Figure 2).

In wild type, Gal4-GH146 labels PNs of three neuroblast lineages. PNs from adPN and IPN lineages target their dendrites to stereotypical, intercalating but non-overlapping sets of glomeruli [2] (Figure 2a1,a2,c1). In general, phenotypes of lola $/$ adPNs and IPNs can be classified into two main categories: a loss of targeting to normal target glomeruli and a gain of targeting to off-target (ectopically targeted) glomeruli (Figure 2b1,b2). However, the phenotypes are highly variable between brains and there are few consistent 'shifts' where one off-target glomerulus is innervated in place of a normal target. The phenotypes also have variable penetrance, with innervation of both normal and ectopic targets ranging from partial to full innervation from brain to brain. Specifically, lola $/$ adPNs often invade DA1, DL3 and VA4, which are normal IPN targets. Likewise, mutant IPNs often innervate VA1d, VA11m, DM6, D, DC2 and VM7, which are normal adPN targets (Figure 2c2). lola- dendrites also appear more diffuse in general, and often 'wander' through the lobe, wrapping around, but not actually innervating, glomeruli. Additionally, lola $\%$ dendrites are frequently not restricted to the $\mathrm{AL}$ and innervate regions of the suboesophageal ganglion (SOG; Figure 2b1,b3,c2). Wild-type vPNs strongly innervate DA1 and VA1lm, and one vPN (pan-AL $\mathrm{PN}$ ) innervates the entire AL (Figure 2a3). lola $\%$ vPNs show a strong loss of AL restriction and nearly $37 \%$ show ectopic dendritic extensions to the SOG (Figure 2b3,c2). Additionally, DA1 targeting in ventral clones is almost completely lost (6\% versus $82 \%$ in wild type) and VA1lm targeting is reduced nearly $30 \%$ (Figure 2c2). We also analyzed an independent lolare5D2 allele of lola, which is predicted to be strongly hypomorphic due to a P-element insertion in the lola promoter (Figure 1b). lola ${ }^{\text {ore } 5 D 2}$ clones display many of the phenotypes observed in the ore 76 null allele (see additional file 1), indicating that the phenotypes we observed are caused by loss of lola.

Given that Lola is ubiquitously expressed, dendritic defects in neuroblast clones can be attributed to its requirement in the neuroblast or post-mitotic cells or both; furthermore, one cannot determine cell autonomy with certainty. We therefore examined single cell clones that target to the DL1 glomerulus to test whether lola has a cell-autonomous and post-mitotic function. We found that nearly $80 \%$ of lola $/$ - DL1 single cell clones show targeting defects (Figure 2b4,c2) and 23\% completely fail to innervate DL1. Another 54\% innervate DL1 (though often weakly or partially) and have additional extensions either wandering between glomeruli or, more frequently, innervating glomeruli anterior to DL1 in the AL (see Table S1 in additional file 2). Using the pan-Lola antibody, we can verify there are no unlabeled clones in the vicinity of the $\mathrm{AL}$ and be certain we are looking at cell-autonomous effects. At least in the DL1 PN, therefore, lola appears to have post-mitotic, cell intrinsic effects on dendritic targeting.

To extend higher resolution phenotypic analysis to other PN classes, we examined adPN and IPN neuroblast clones using Gal4-Mz19, which labels a small subset of GH146- 

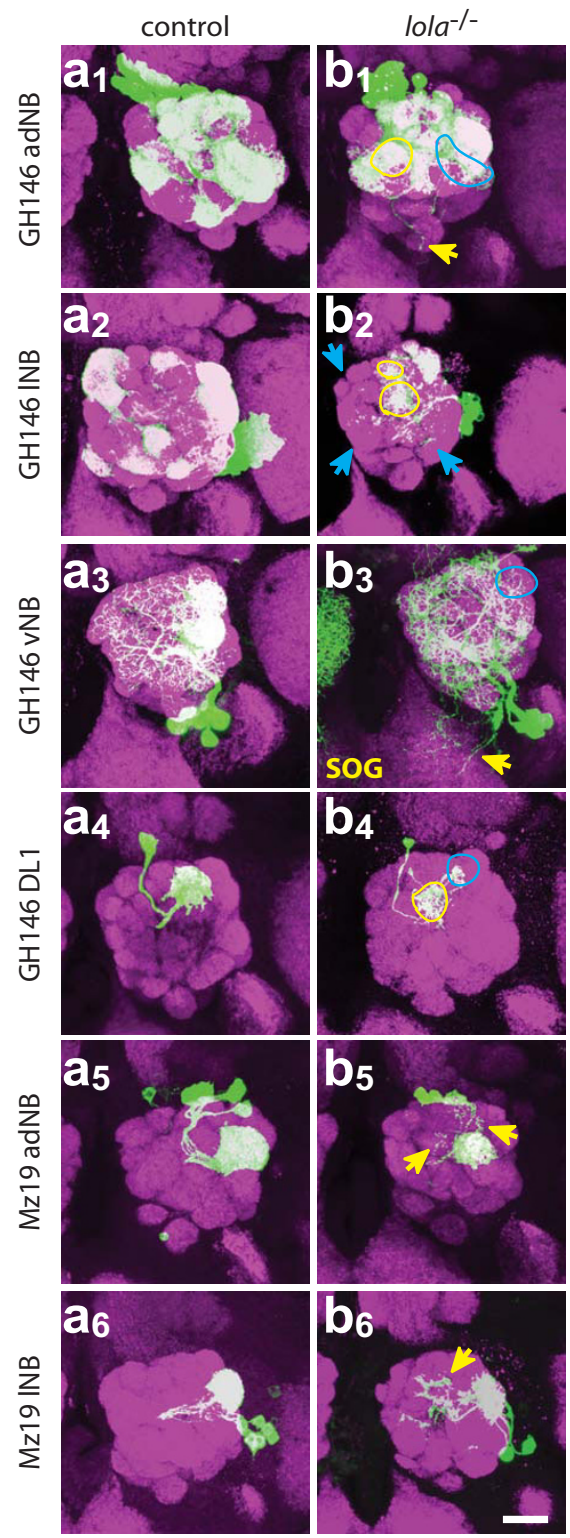

C1 Gal4-GH146 AL Glomerular Targets
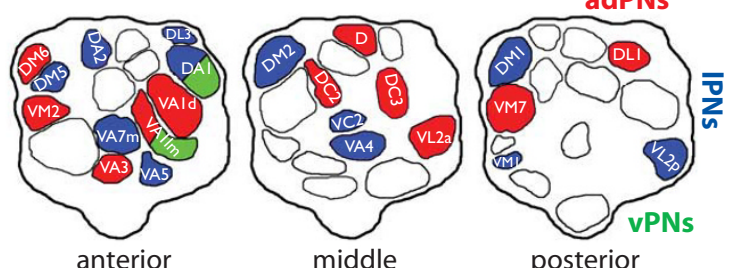

$\mathrm{C}_{2} \%$ Targeting in Gal4-GH146 Clones
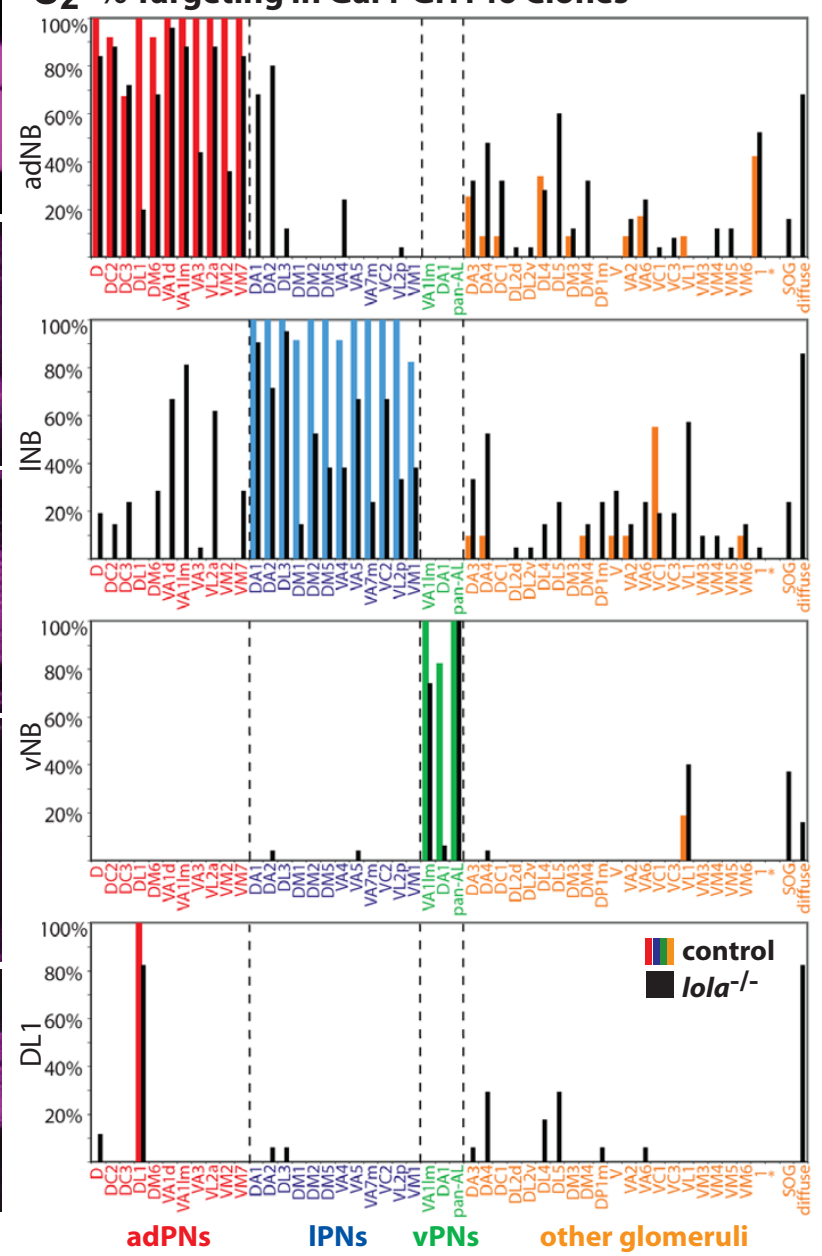

Figure 2

Dendritic targeting defects in lola-l-MARCM clones. Representative confocal images of (a) wild-type control and (b) lola-/anterodorsal (I), lateral (2), or ventral (3) MARCM neuroblast (NB) clones or DLI single cell (SC) clones (4) labeled with Gal4-GHI46, and anterodorsal (5) and lateral (6) neuroblast clones labeled with Gal4-MzI9. Blue arrows and circles demark a loss of correct targeting, while yellow arrows and circles demark off-target innervation. Both anterodorsal and ventral lola-/clones have ectopic dendritic extensions to the suboesophageal ganglion (SOG). anti-CD8::GFP in green, anti-nc82 neuropil in magenta. Scale bar, $20 \mu \mathrm{m}$. ( $\left.\mathbf{c}_{\mathbf{l}}\right)$ Normal targets of Gal4-GHI46 in anterior, middle and posterior sections of the AL. Red denotes dorsal target, blue denotes lateral target, and green denotes ventral target. ( $\left.\mathbf{c}_{2}\right)$ Quantification of adNB, INB, vNB and DLI clone phenotypes. The percentage of clones targeting a particular glomerulus is denoted on the $\mathrm{Y}$-axis, while individual glomeruli are listed on the $\mathrm{X}$-axis and grouped according to lineage by color as in $\left(\mathrm{c}_{1}\right)$. Glomeruli in orange are not normally targeted by Gal4-GHI46 positive PNs by heatshocking at $24 \mathrm{~h}$ ALH. Control clone innervation is denoted by colored bars corresponding to lineage, and $/ \mathrm{lo}^{-/-}$clone innervation is denoted by black bars. Note the decrease of correct targeting and increase of off-target innervation in lola-/-brains for all clone types. Additionally, the final 'diffuse' bar quantifies the number of brains that exhibit diffuse and wandering dendrites that fail to specifically innervate glomeruli. 
positive neurons that project to DA1, VA1d and DC3 [4]. Interestingly, dendritic targeting of lola $\%$ DA1 and VA1d PNs exhibit phenotypes with much less severity and penetrance than other lola ${ }^{-}$- PNs. Normal target glomeruli were almost always strongly targeted, and defects mainly consisted of additional dendritic extensions into the $\mathrm{AL}$ (Figure 2b5,6). Consistent with this, we find that DA1 (innervated by lPNs) and VA1d (innervated by adPNs) are two of the most 'stable' glomeruli and show little phenotype in GH146 mutant neuroblast clones (Figure 2c2). These two glomeruli are also often ectopically innervated by lola $\%$ PNs from the opposite lineage (that is, DA1 is ectopically targeted by lola $\%$ adPNs while VA1d is ectopically targeted by lola-/lPNs). This experiment suggests that distinct PN classes differentially require lola.

We also tested available mutations that affect individual lola isoforms. The orc4 (affecting isoform K; Figure 1b) allele did not show obvious defects (see additional files 1 , 4 and 8). The ore 119 allele (affecting isoform L; Figure 1b) shows a small subset of the phenotypes observed in lola $\%$ (see additional file 1). lola $\mathrm{L}^{-1}$ - adPN targeting appears normal, but IPNs show a loss of targeting to VM1 and DA2, while ventral clones show a loss of DA1 targeting. However, we cannot rule out the possibility that an additional mutation on the lola $L$ mutant chromosome contributes to the phenotype, as our attempts to generate a second allele specific for lola $L$ have not been successful and the ore119 phenotype could not be rescued by a UAS-lola $L$ transgene (data not shown). In fact, MARCM expression of lola $L$ in PNs results in severe phenotypes by itself (see below).

lola mutant projection neurons have axon wiring defects In addition to dendritic phenotypes, we observed defects in PN axonal wiring in lola-MARCM clones. As with dendrites, defects were found in adPNs, IPNs and vPNs as well as DL1 single-cell clones (Figure 3). Phenotypes were highly variable both in penetrance and severity in neuroblast as well as single cell clones. In a semi-quantitative approach, we scored phenotypes as mild, medium and severe (see Figure 3 legend). A separate quantification of the targeting defects limited by specific phenotypes (ectopic branching, misrouting of axons, SOG targeting and a lack of $\mathrm{MB} / \mathrm{LH}$ innervation) is presented in Table S2 (see additional file 2).

In lola $/$ adPNs and IPNs, the most common defect was ectopic branching outside of the region of the $\mathrm{MB}$ or the LH (28\% and 63\%, respectively; Figure 3b1,2; see Table S2 in additional file 2). Some clones showed a lack of innervation, where innervation of the MB failed to occur or branch extension in the LH was severely limited. A smaller percentage of lola $\%$ clones (15\% adPNs and $7 \%$ PNs) showed medium or severe axon defects (Figure $3 \mathrm{~d}$ ).
Hypomorphic clones (ore5D2) show similar, but mostly mild, targeting defects (see Table S2 in additional file 2).

Axons of vPNs are the most severely affected: nearly $100 \%$ of clones exhibit defects in both lola $\%$ and hypomorphic (ore5D2) alleles (Figure 3b3,d; see Table S2 and S4 in additional file 2). Often ventral axons show several defects in the same brain. Seventy-nine percent of lola-/clones show ectopic branching defects (often extensions from the LH towards the SOG or an increase in branches along the medial extension). Thirty-four percent of clones show misrouting defects; most often a single axon defasciculates from the bundle and projects directly to the medial-central region of the LH instead of the ventral region (compare Figure $3 \mathrm{a} 3$ to $3 \mathrm{~b} 3$ ). Nine percent of null clones and $47 \%$ of hypomorph clones show clear axonal targeting to the SOG (this may be higher in the null but it can be difficult to distinguish between axon and dendrite mistargeting unless clear defasciculation from the main axon bundle is visible). We observe that all PN axons exit the AL in a single bundle, but then some axons defasciculate and project ventrally to the SOG (Figure 3c). It is interesting to note that axons misguided to the SOG typically project to similar locations in the SOG, suggesting they may be responding to some cues in this region.

More than $50 \%$ of DL1 single cell clones show axon defects (Figure 3b4,d, see Table S3 in additional file 2), suggesting that Lola acts cell-autonomously in axon targeting. Twenty-six percent of DL1 lola-/- axons have ectopic branches, often with additional branches in the LH region (see Table S2 in additional file 2). Fifteen percent of clones fail to extend branches into the MB (see Table S2 in additional file 2). Some DL1 axons clearly bifurcate just prior to entering the MB. It is interesting to note that many DL1 clones that fail to target the DL1 glomerulus have relatively normal axonal projections. A severe dendrite phenotype does not predict the most severe axon phenotypes (or vice versa), suggesting that these two processes are separable, in agreement with recent observations of independence between axon and dendrite targeting [14]. These results suggest that lola has post-mitotic, cell-autonomous functions in PN axon targeting.

\section{Analysis of lola isoform expression by in situ hybridization and $R T$-PCR}

Our MARCM analysis suggests that lola has an important function for PN dendritic and axonal targeting. Given that lola encodes 20 alternatively spliced isoforms, several scenarios may account for lola function (see additional file 3). In scenario I, different isoforms may be expressed in different neuroblast lineages and thereby specify their lineage-specific wiring analogous to POU transcription factors [13]. In scenario II, individual PNs may express a unique isoform or combination of isoforms independent 

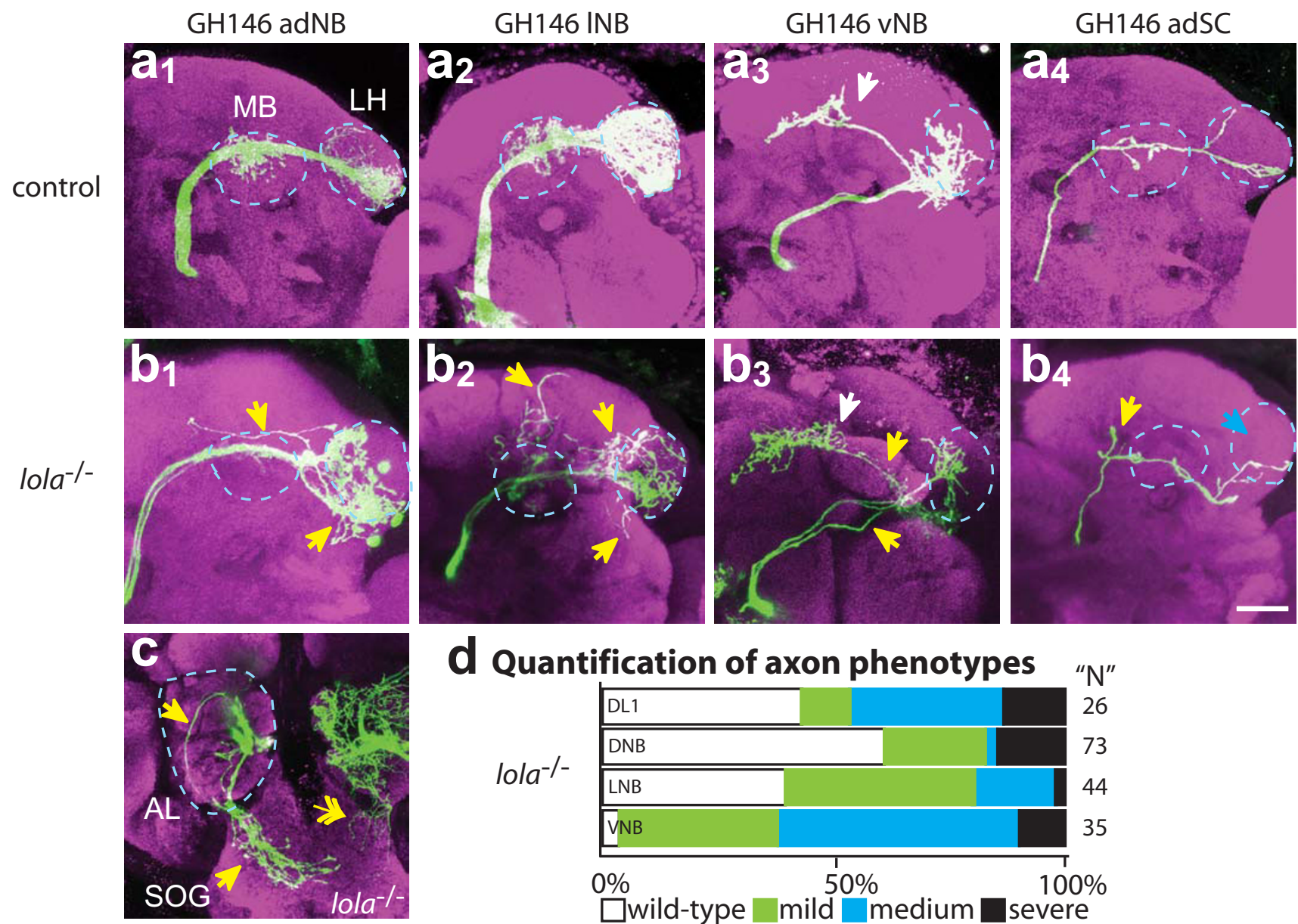

\section{Figure 3}

Axon wiring defects in lola-/-MARCM clones. Representative confocal images of (a) wild-type control and (b) lola-/- adNB (I), INB (2) vNB (3) and DLI SC (4) clones showing PN axons near their normal target: the mushroom body (MB) and lateral horn (LH), both marked by blue dotted circles. (c) Example of an axon mistargeting to SOG after exiting the posterior AL (blue dotted circle). Double-headed white arrow demarks dendritic mistargeting to SOG. Blue arrows denote a lack of correct targeting while yellow arrows demark ectopic branching. anti-CD8::GFP in green, anti-nc82 neuropil in magenta. Scale bar, $20 \mu \mathrm{m}$. (d) Quantification of severity of axon targeting defects. Mild: axons target correctly but have ectopic branches $\left(b_{1}\right.$, $\left.b_{2}\right)$; medium: axons target to the correct region but follow an incorrect trajectory or bifurcate $\left(b_{3}, b_{4}\right)$; severe: axons target to the SOG or abnormal brain regions (c).

of lineage to specify PN identity. In scenario III, all cells may express most or all lola isoforms.

To distinguish between these possibilities, we performed RNA in situ hybridization with probes against 16 of the 20 lola isoforms at $0 \mathrm{~h}$ after puparium formation (APF), a developmental time when PNs start to elaborate dendrites in the AL [4]. We first verified our in situ protocol by using probes against drifter $(d f r)$, a TF that has previously been shown to be expressed in GH146 labeled IPNs but not adPNs [13]. As expected, we found that signal from antisense probe against $d f r$ mRNA coincides with green fluo- rescent protein (GFP)-labeled IPNs but not adPNs (see additional file 3 ). A sense control probe shows little signal coinciding with the GFP-positive cell bodies (see additional file 3 ). We then performed in situ analysis with lola probes. A probe to the lola common region shows expression throughout the brain (Figure 4a1,a3) compared with sense control (Figure 4a2), consistent with our Lola antibody staining results. For individual isoform mRNAs, we detect signal in the region of the AL for all lola isoforms tested, as well as other brain regions. Some isoforms have narrower domains of expression, such as isoforms $\mathrm{N}$ (see additional file 3 ) and $\mathrm{T}$ (Figure $4 \mathrm{~d} 1, \mathrm{~d} 3$ ), which have much 
stronger signal in the central brain and weaker staining in the optic lobe. Other isoforms appear to be expressed more uniformly throughout the region of the AL (Figure 4 ; see additional file 3 ). It should be noted that several isoforms have more punctate signal that co-localizes with the nucleus (see additional file $3 \mathrm{f}, \mathrm{k}, \mathrm{r}$ ), perhaps indicative of pre-mRNA. Another caveat is that mRNA production may not translate to protein expression, as recently shown by the wide mRNA but narrow protein expression domains of nerfin [31]. We did not find PN lineage-specific expression for any of the lola isoforms, nor is there evidence that any isoforms are expressed in a subset of PNs within a lineage. Rather, most lola isoform mRNAs appear to be expressed in all PNs, consistent with scenario III (see additional file 3 ).

As an independent and more quantitative method of assessing expression of different isoforms in PNs, we performed laser-dissection microscopy (LCM) to capture GH146-positive PNs from frozen sections of $0 \mathrm{~h}$ APF tissue, followed by quantitative RT-PCR to detect the expression level of individual isoforms. Although we do not have single-cell resolution, laser-dissection allows us to assay mRNA expression in a small subset of neurons. Consistent with the in situ hybridization data, at $0 \mathrm{~h} \mathrm{APF}$ we detected most lola isoforms by RT-PCR, although several isoforms are near the RT-PCR detection limit (Figure 4e). We find marked differences (up to 100-fold) in the level of RNA expression of individual isoforms in PNs at $0 \mathrm{~h}$ APF (Figure 4e). We additionally analyzed AL samples from different developmental timepoints (third instar larvae, $0 \mathrm{~h} \mathrm{APF}, 25 \mathrm{~h}$ APF and adult) and find that expression levels of several lola isoforms, for example isoform E, H, I, $\mathrm{L}, \mathrm{M}$ and $\mathrm{Q}$, appear to be developmentally regulated (see additional file 4). Our in situ results also suggested that lola isoforms are expressed at different levels in the optic lobe. Indeed, RT-PCR on LCM captured optic lobe at $0 \mathrm{~h}$ APF confirmed that mRNAs of different lola isoforms are expressed at different levels and revealed differences in the pattern of isoform expression between $\mathrm{AL}$ and optic lobe samples (see additional file 4). Together, these data suggest that the level of individual lola isoform expression is dynamically regulated and that individual isoforms may function at different stages in development.

\section{UAS-lola transgene overexpression phenotypes}

Genetic analysis using available isoform-specific alleles (see additional file 1) indicates that at least two isoforms ( $\mathrm{K}$ and $\mathrm{L}$ ) are not required for dendritic targeting of the majority of PN classes. To test further potential functions of different isoforms, we examined the overexpression phenotypes of three lola isoforms. Previous reports suggested differences between the overexpression phenotypes of lola $A$ and lola $T$ in motor neurons [25]. We have generated a third transgene, UAS-lola L. We found that Gal4-
GH146 expression of any of these three UAS transgenes results in lethality, but we bypassed this lethality by MARCM mediated transgene expression in specific neuroblast lineages or single cells (Figure 5; see additional file 5 ). We tested one, three and two insertions for UAS-lola A, UAS-lola $L$ and UAS-lola $T$, respectively (see Table $S 1$ in additional file 2). Levels of transgene expression were verified in our attempted rescue experiments (see below). Because Gal4-GH146 drives transgene expression in postmitotic PNs (J Liu, MS, LL, unpublished observation), the overexpression phenotypes we describe below are caused by post-mitotic expression of lola transgenes.

Neuroblast or single cell clones overexpressing UAS-lola A (which lacks a Zn-finger) do not exhibit detectable defects (Figure 5b; see additional file 5). However, UAS-lola $L$ and UAS-lola $T$ (which both have $\mathrm{C}_{2} \mathrm{HC}-\mathrm{C}_{2} \mathrm{H}_{2}$-type $\mathrm{Zn}$-fingers) show strong targeting defects in adPN and IPN neuroblast clones (see additional file 5). Phenotypes often include a large increase in wandering dendrites in the AL and some degree of loss of targeting and ectopic targeting. Often dendrites appear to be largely restricted to one region of the AL such as dorsal or lateral, and have wandering dendrites through this region in many glomeruli, but fail to innervate normal targets or extend any dendrites into other regions of the AL (see Additional file 5c, e, f). UASlola $T$ expression also results in a decrease in the number of labeled PNs, in part likely due to cytotoxicity based on the observation of clones with very punctate GFP staining patterns indicative of cell and process degeneration, although we were unable to reliably stain brain tissues for activated caspase-3 (V Trunova and E Giniger, unpublished data). Due to the difficulty in quantifying phenotypes in adPN and IPN neuroblast clones because of the magnitude and variability, we focused our analysis on vPN neuroblast clones and single-cell DL1 clones.

vPN neuroblast clones in animals raised at $25^{\circ} \mathrm{C}$ show no defects when overexpressing lola $A$ (Figure 5b1) and weak phenotypes when overexpressing lola $L$ (Figure $5 \mathrm{c} 1$ ), but vPNs are strongly affected by lola $\mathrm{T}$ overexpression (Figure $5 e 1, f 1)$. Targeting to DA1 is often lost in vPN clones overexpressing lola $T$ (Figure 5e1,f1,g). vPN dendrites frequently extend outside of the AL boundary, most often in the ventral region projecting towards the SOG. Processes of the pan-AL vPN are not elaborated properly and only partially innervate the AL.

DL1 single-cell clones were used to examine cell-autonomous overexpression effects on both dendritic and axonal targeting. lola A overexpression did not affect targeting of either DL1 axons or dendrites (Figure 5b2,b3). The DL1 dendrites targeted correctly with lola $L$ overexpression, but frequently showed a large increase in dendritic mass outside of DL1, wandering throughout the AL (Figure $5 c 2, \mathrm{~h}$ ). 


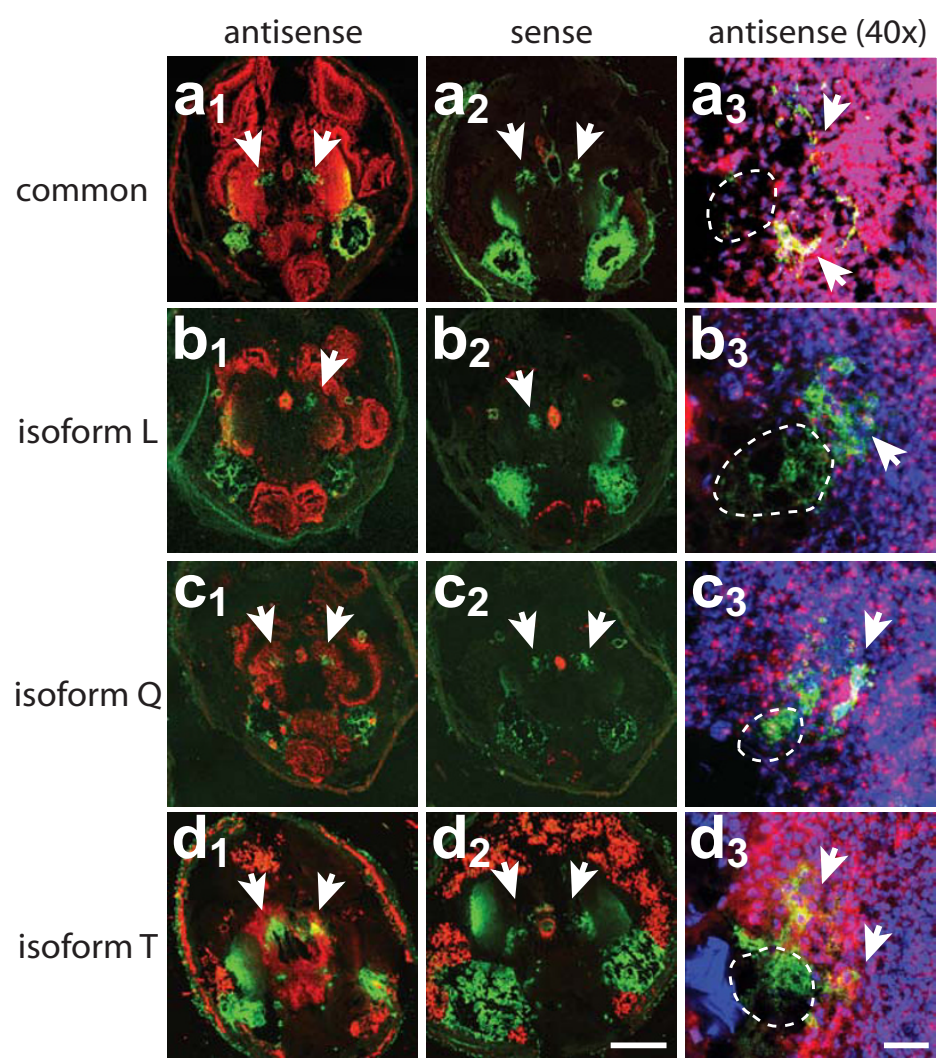

\section{C individual isoform RT-PCR analysis}

RNA DAPI GFP

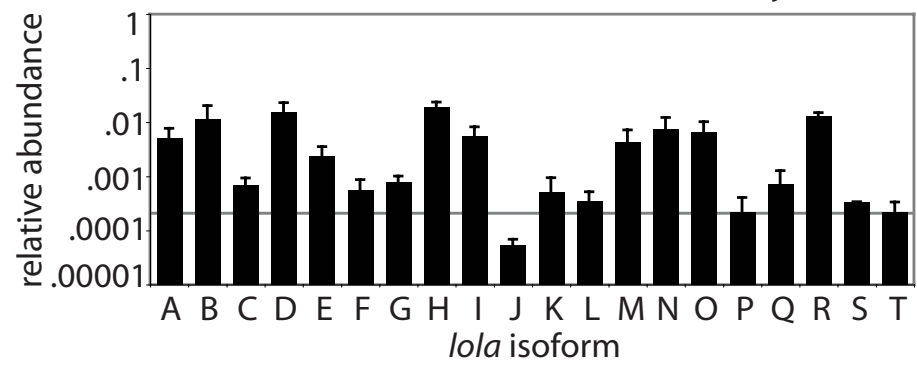

\section{Figure 4}

Expression of lola isoforms in the Drosophila brain. (a-d) RNA in situ analysis of lola isoforms. $\left(\mathrm{a}_{1}\right)$ An antisense probe generated against the common region of lola labels uniformly throughout the brain at $0 \mathrm{~h}$ APF. $\left(\mathrm{a}_{2}\right) \mathrm{A}$ sense control to the same probe shows little specific staining. $\left(a_{3}\right)$ A magnified view of the AL reveals lola expression in all PN cell bodies. PN cell bodies are marked by white arrows, while dotted while lines demark the rough area of the AL neuropil in each section that is not stained by DAPI. Midline to the left, lateral to the right. Isoform specific probes to isoform L (b), isoform $Q$ (c) and isoform $T$ (d) show different patterns of expression throughout the brain at $0 \mathrm{~h}$ APF, while sense control probes $\left(b_{2}-d_{2}\right)$ show little specific labeling. Closer inspection of $A L$ regions at a higher magnification $\left(b_{3}-d_{3}\right)$ reveals that most isoforms appear to be expressed in PNs. Scale bars: $20 \mu \mathrm{m}\left(\mathrm{a}_{3}-\mathrm{d}_{3}\right) ; 200 \mu \mathrm{m}\left(\mathrm{a}_{1}-\mathrm{d}_{2}\right)$. DIG-labeled RNA probe in red, DAPI in blue, GFP in green. See Additional file 2 for in situ analysis of additional lola isoforms and additional labeling of section morphology. (e) Quantitative RT-PCR of laser-captured PN enriched-samples verifies in situ results that most isoforms are expressed in PNs. Additionally, different lola isoforms are expressed at different levels at $0 \mathrm{~h}$ APF, with about 100 -fold difference between highest and lowest expression levels. Data are displayed by lola isoform on the $\mathrm{X}$-axis and by relative abundance on a log scale on the $\mathrm{Y}$-axis, where relative abundance has been determined against the level of actin42 expression. Error bars represent the standard deviation from four independent samples, and each sample was tested independently five times per device. Horizontal solid line represents a confidence limit of the average relative expression of samples near the detection limit based on CT values and reproducibility. 


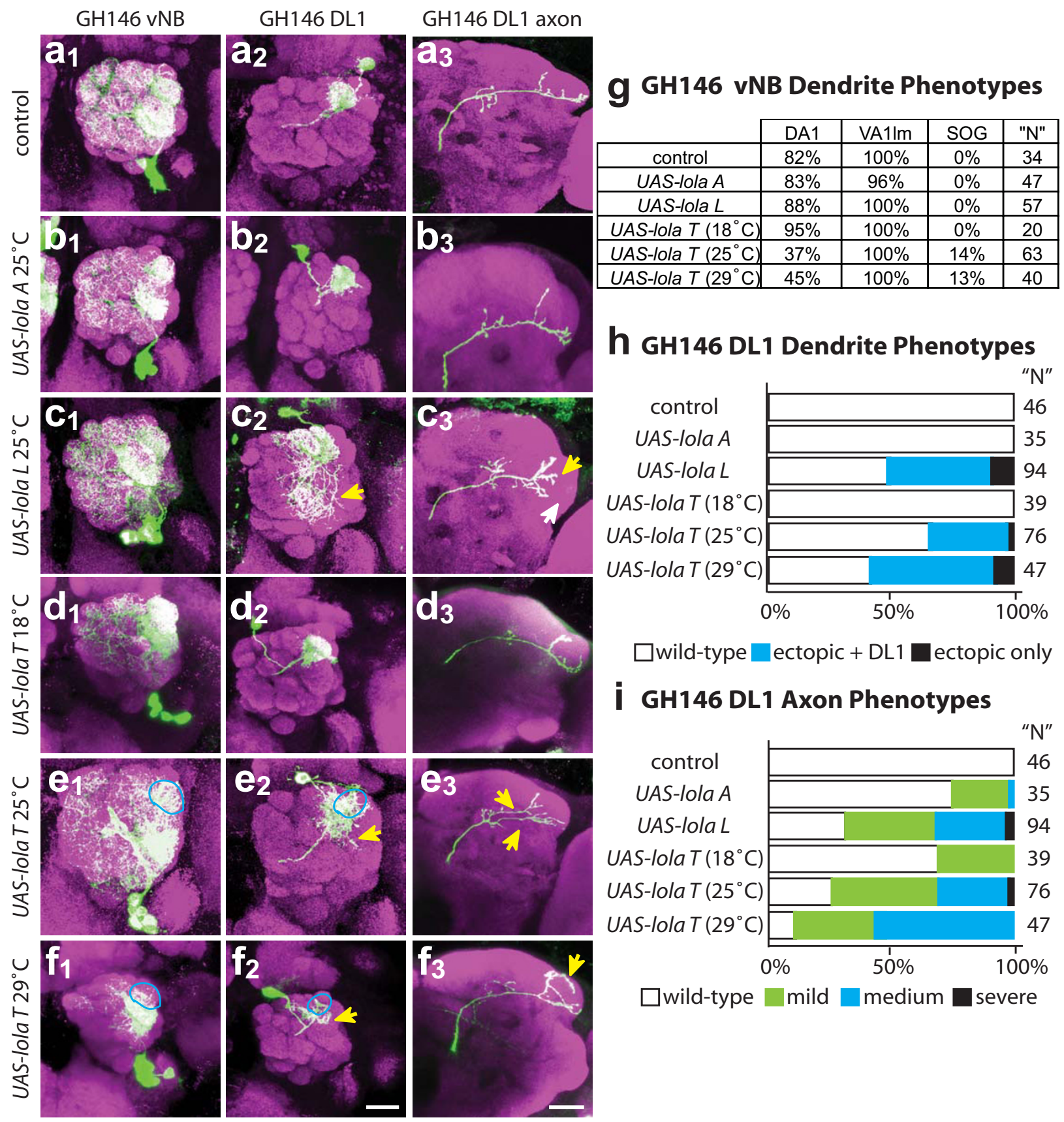

\section{Figure 5}

Effects of overexpressing different lola isoforms on dendritic and axonal phenotypes. Representative confocal images of (a) control and (b-f) Gal4-GHI46 MARCM overexpression phenotypes in vNB (I), DLI (2) and DLI axon (3). UAS-lola A (b) overexpression shows little defects, whereas UAS-Iola $L$ (c) and UAS-lola $T$ (d-f) show defects in most classes of PNs. The effect of UAS-Iola $T(\mathrm{~d}-\mathrm{f})$ expression increases with increasing temperature. anti-CD8::GFP in green, anti-nc82 neuropil in magenta. Scale bar, $20 \mu \mathrm{m}$. Blue circles demark a loss of correct targeting, while yellow arrows demark off-target innervation or branching. (g) Quantification of vNB targeting phenotypes. Data are presented as percentage of observed clones that innervate a given target. Overexpression of UAS-lola $\mathrm{T}$ at $25^{\circ} \mathrm{C}$ or $29^{\circ} \mathrm{C}$ results in a decrease in DAI targeting and an increase in ectopic dendritic extensions to the SOG. (h, i) Quantification of DLI phenotypes. Dendrite defects are quantified (h) by percent of clones that fail to target DLI and those that target DLI but have additional dendrite extensions and ectopic innervations in the AL. Axon defects (i) are quantified as in Figure 3. 
In axons, overexpression of lola $L$ often resulted in an increase in branching in $\mathrm{MB}$ and $\mathrm{LH}$ regions (Figure $5 \mathrm{c} 3, \mathrm{i})$. In the $\mathrm{LH}$, these additional branches resulted in a loss of the stereotypic ' $\mathrm{L}$ ' projection and a failure of branches to fully extend into normal target areas. lola $T$ overexpression resulted in variable DL1 phenotypes, ranging from a complete loss of DL1 innervation and targeting to other regions of the AL to DL1 targeting with dendritic extensions outside of the DL1 glomerular region (Figure $5 e 2, f 2, \mathrm{~h})$. lola $\mathrm{T}$ overexpression also affected axon targeting, most often resulting in a high degree of ectopic branching, axon bifurcation and incorrect LH innervation patterns (Figure $5 e 3, \mathrm{f3}, \mathrm{i}$ ). It is interesting to note that isoforms L and $\mathrm{T}$ are normally expressed at low levels based on RT-PCR results, while isoform A is expressed roughly 10 -fold higher (Figure 4e). Differences in overexpression phenotype may be related to the presence or absence of a Zn-finger domain, and/or to the expression level relative to the endogenous level of expression.

\section{UAS-lola T dosage sensitivity}

In the course of our overexpression study, we tested two different insertions of UAS-lola $T$. We noticed that the insertion on the third chromosome gives stronger and more penetrant phenotypes than the insertion on the $\mathrm{X}$ chromosome, and hypothesized that this was due to differences in transgene expression levels. To test this hypothesis, we altered the levels of UAS-lola $T$ (X insertion) transgene expression by raising animals at $18^{\circ} \mathrm{C}, 25^{\circ} \mathrm{C}$ or $29^{\circ} \mathrm{C}$, as levels of Gal4-induced transgene expression increase with increasing temperatures. In neuroblast clones we observed a qualitative increase of phenotypic severity in both dendritic and axonal targeting with increasing temperature (Figure $5 \mathrm{~d}, \mathrm{e}, \mathrm{f}$ ). This dosage sensitivity can be quantified with the DL1 dendritic phenotypes (Figure $5 \mathrm{~h}$ ). Flies raised at $18^{\circ} \mathrm{C}$ have few dendritic phenotypes, while at $25^{\circ} \mathrm{C}$ and $29^{\circ} \mathrm{C}$ dendrites mistarget and have ectopic innervations and axons have additional branches and bifurcations (Figure 5h,i; see Table S1 in additional file 2). Additionally, dosage sensitivity is evident in vNB DA1 and SOG extension phenotypes (Figure $5 \mathrm{~g})$. This experiment indicates that PN dendritic targeting is sensitive to the expression level of a specific lola isoform.

Individual lola isoform expression in a lola null background To test if individual lola isoforms can rescue any of the lola/- phenotype, we performed MARCM analysis on clones that are simultaneously lola $\%$ and express either UAS-lola A, UAS-lola $L$ or UAS-lola $T$ transgenes. We verified all transgenes are expressed based on the presence of Lola antibody staining in these otherwise lola $/$ clones. Expression of all transgenes was qualitatively similar at a level roughly half as intense as neighboring non-mutant cells expressing endogenous levels of Lola (data not shown).
Instead of rescuing the lola-/- phenotype, overexpression of transgenes in mutant PNs resulted in additive defects (Figure 6; see additional file 6). In adPN and IPN neuroblast clones, simultaneous loss of endogenous lola and expression of any of the single isoforms caused striking additive effects in cell loss and lack of dendritic extension, which are described in detail in additional file 6 . Below we focus on vPN neuroblast clones and DL1 single cell clones.

Additive effects of transgene expression were most striking in vPNs. lola $\%$ vPNs expressing UAS-lola A, UAS-lola L or $U A S$-lola $T$ resulted in strong reduction of VA1lm and DA1 targeting (Figure 6f). Additionally, the pan-AL neuron often showed little dendritic process elaboration and rarely innervated much of the AL. Dendrites and axons of ventral cells often looked punctate, indicative of degeneration. These data indicate that expression of UAS transgenes in lola $\%$ clones fails to rescue lola phenotypes and further disrupts dendritic wiring. Additionally, expression of certain lola isoforms alone may be toxic, perhaps due to dominant-negative interactions with other proteins or lola dimerization.

DL1 clones were difficult to obtain for all UAS-lola transgenes expressed in lola $\%$ clones, possibly due to toxicity that we observe in neuroblast clones. Phenotypes did not always appear additive for DL1 clones, perhaps due to low levels of MARCM-based expression in single cell clones during the critical time of dendritic and axonal targeting. The strongest dendritic phenotypes were observed in lola/- cells expressing UAS-lola $T$, where every clone either failed to innervate DL1 or had extensions into other regions of the AL (Figure 6e,g). lola $/$ - cells expressing UASlola $L$ innervated DL1 in addition to having extensive dendritic innervation in the rest of the AL, while lola- cells expressing UAS-lola $A$ were variable, with half appearing normal (Figure 6c,d,g). All lola $/$ cells expressing a UASlola transgene showed axonal defects, ranging from a failure to extend or elaborate branches in the LH to an increase in ectopic branching (Figure 6h). These phenotypes suggest that individual lola isoforms can function post-mitotically to disrupt dendrite and axon targeting in DL1, and suggest that Lola interacts either as homomers or with other BTB domain proteins. Additionally, expression of single lola isoforms, especially lola $T$, appears to be toxic to many cells, so it is unclear if phenotypes are directly related to targeting or perhaps secondary effects due to disruption of cell viability.

Taken together, these results suggest that isoform diversity of the lola locus is important. Post-mitotic expression of a single isoform is not sufficient to rescue the lola phenotype, and indeed is more disruptive to a cell than simple loss of lola. This does not, however, rule out an additional function of Lola in the neuroblast. Lastly, some aspects of 

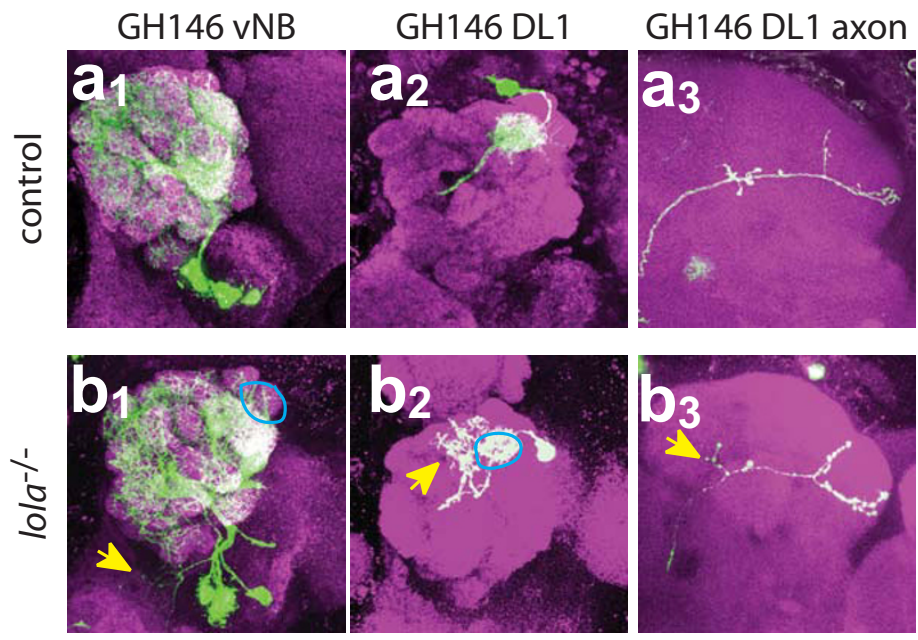

f GH146 vNB Phenotype (\% innervated)
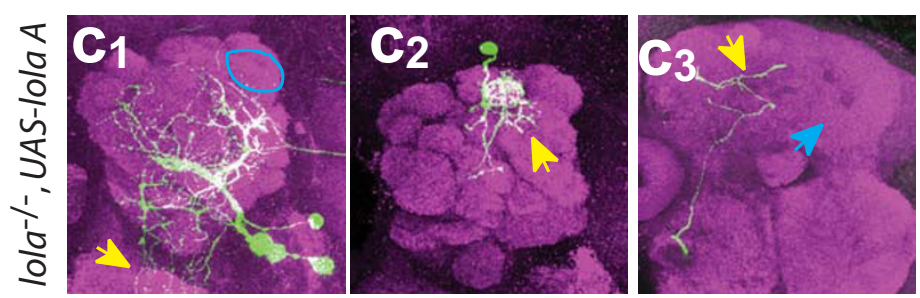

\begin{tabular}{|c|c|c|c|c|}
\cline { 2 - 5 } \multicolumn{1}{c|}{} & DA1 & VA1Im & SOG & "N" \\
\hline control & $82 \%$ & $100 \%$ & $0 \%$ & 34 \\
\hline lola $^{-/-}$ & $6 \%$ & $74 \%$ & $37 \%$ & 35 \\
\hline lola $^{-/-}$, UAS-lola A & $0 \%$ & $17 \%$ & $33 \%$ & 12 \\
\hline lola $^{-1-}$, UAS-lola L & $14 \%$ & $86 \%$ & $29 \%$ & 7 \\
\hline lola $^{-/-}$, UAS-Iola T & $0 \%$ & $20 \%$ & $40 \%$ & 5 \\
\hline
\end{tabular}

\section{GGH146 DL1 Dendrite Phenotypes}
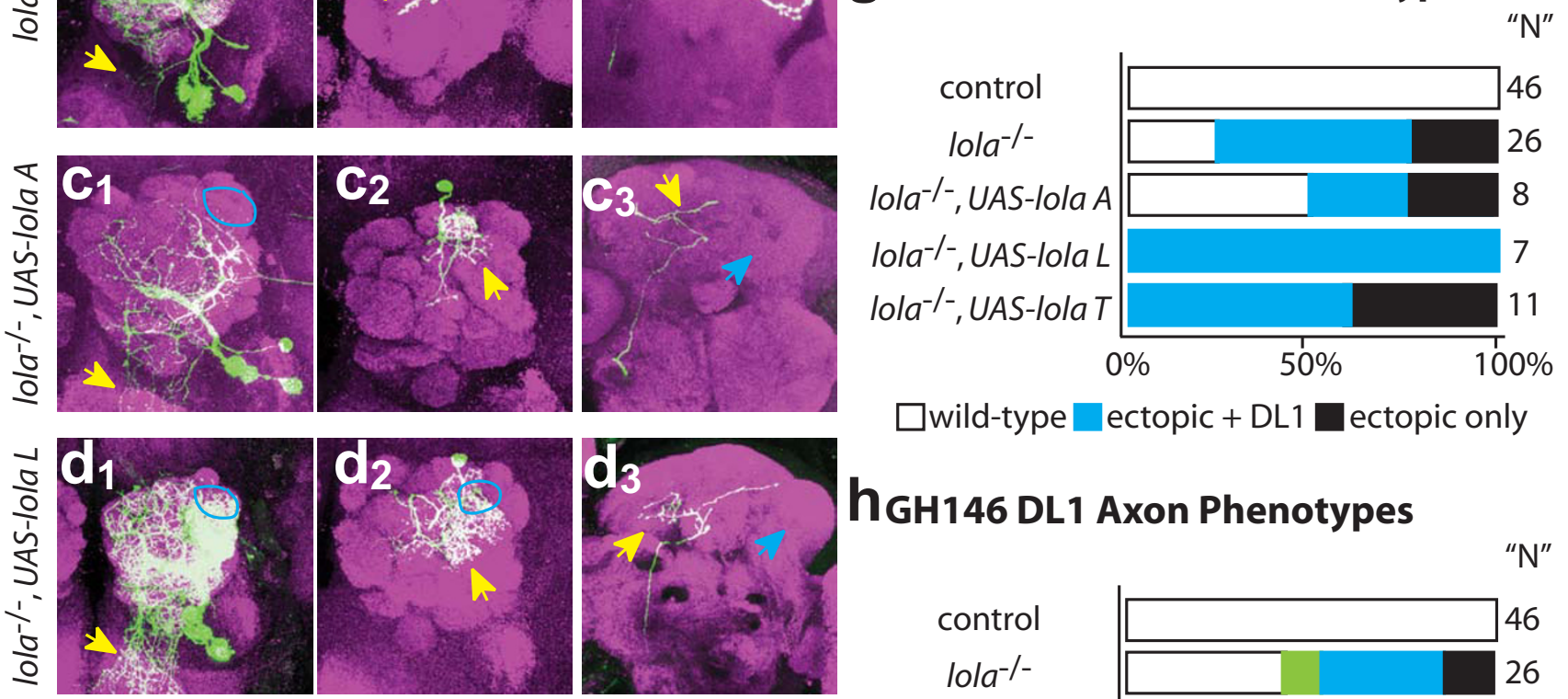

$\square$ wild-type $\square$ ectopic + DL1 $\square$ ectopic only

\section{hGH146 DL1 Axon Phenotypes}

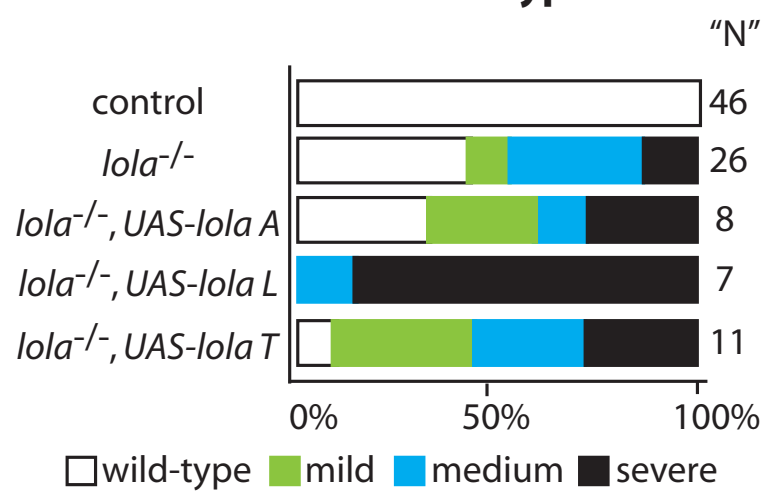

\section{Figure 6}

UAS-transgene overexpression in lola-/- MARCM clones results in additive dendritic and axonal targeting defects. Representative images of (a) control and (b-e) experimental conditions as indicated for the vNB (I), DLI single-cell dendrite (2) and axon (3) phenotypes of UAS-lola A (c), UAS-lola L (d) and UAS-lola T (e) expression in lola-l-MARCM clones. None of the transgenes are able to rescue the lola-/- phenotype. Expression of either UAS-lola $A$ and UAS-Iola $T$ both result in a decrease in dendrite elaboration. (f) Quantification of vNB phenotypes. Data are presented as percentage of observed clones that innervate a particular target. UAS-lola transgenes fail to rescue the lola-l- phenotype. Often transgene expression has an additive effect and further disrupts normal targeting, for example, there are dramatic losses of VAllm targeting with UAS-lola A and UAS-lola T. ' $\mathrm{N}$ ' for rescue experiments are low due to extreme difficulty in generating MARCM UAS-expression clones in a lola-l- background. (g) Quantification of DLI dendrite phenotypes as in Figure 5. UAS-lola $L$ and UAS-lola T clones lack normal dendritic targeting. (h) Quantification of DLI axonal phenotypes as in Figure 2. UAS-lola $L$ and UAS-lola $T$ show increases in axonal defects compared with lola- $^{-1}$ alone. anti-CD8::GFP in green, anti-nc82 neuropil in magenta. Scale bar, $20 \mu \mathrm{m}$. 
Lola function are likely mediated through the BTB domain alone, as additive phenotypes can be caused by expressing isoforms with or without $\mathrm{Zn}$-fingers.

Evidence that lola regulates cell identity and transcription The dendritic and axonal phenotypes in lola $\%$ clones we described so far could be caused by the action of Lola on PN targeting directly (for instance, by regulating the expression of cell surface receptors), or Lola could regulate PN identity with axonal and dendritic mistargeting as a secondary consequence. Although these models are not mutually exclusive, we provide some evidence in lola-/MARCM clones using several Gal4 lines, including Mz19, GH146 and NP3529, to support the second hypothesis.

MARCM with several mutant alleles suggests that lola regulates the expression of Gal4-Mz19. Ten percent of lola ore5D2 (lola hypomorph) and lola $\%$ clones show a 30\% to $50 \%$ increase in the number of labeled PNs and targeted glomeruli (Figure 7a2,a3; MARCM control Figure $2 \mathrm{a} 5, \mathrm{a} 6$ ). Strikingly, we observed (in $64 \%$ of all adPN clones) that lola $\mathrm{L}^{-/}$(lolaore119) clones frequently target the DL1 glomerulus (Figure 7a5), which is normally targeted by GH146 positive, but never Mz19 positive, PNs. As our heat-shock timing in these experiments should not result in any Mz19 single cell clones (they are born later) but coincides exclusively with the birth of the DL1 PN [2], the simplest interpretation is that Mz19 is now misexpressed in DL1 PNs. This would suggest that lola normally represses Mz19 expression in DL1 PNs. As additional evidence that lola regulates gene expression, $25 \%$ of clones of both lola $\%$ and lola $\mathrm{L}^{-/}$-visualized by Gal4-Mz19 appear to label local interneurons (LNs), an additional cell-type that innervates a large number of glomeruli in the AL and lacks axonal projections out of the AL region (Figure 7a4,a6). The similarity of isoform L specific phenotypes to phenotypes in other lola alleles suggests that lolare119 phenotypes in PNs might be caused by the disruption in isoform L instead of a second site mutation on the same chromosomal arm. Thus, it appears that in the absence of Lola (particularly the Lola L isoform), Gal4-Mz19 is ectopically expressed in neuronal types that normally do not express this Gal4 enhancer trap line.

Gal4-GH146, used extensively in this study, labels a large subset of PNs in the AL, roughly 50 adPNs, 35 lPNs and 5 or 6 vPNs (Figure 7b1; MARCM controls Figure 2a1-3). However, in lola $\%$ neuroblast clones we observe labeling of a new cell type that innervates a small region of the $\mathrm{AL}$ and sends projections to the medial axonal lobe of the $\mathrm{MB}$ as well as the central body complex (Figure 7b2-3). These cells are never labeled in control experiments, but make up $22 \%$ of all observed clones in lola $\%$ experiments (see Table S5 in additional file 2). Interestingly, we observe similar projection patterns in wild-type neurons labeled with other Gal4 drivers, suggesting that central body complex targeted lola $\%$ clones are a different cell type where Gal4-GH146 expression is normally repressed by lola.

Gal4-NP3529 labels two dorsal PNs that project to DL1 (Figure 7c1). Clones generated with both lola- and lola $\mathrm{L}^{-}$ 1- label much larger subsets of cells. These clones often contain PNs that innervate typical GH146 target glomeruli, as well as LNs and other PN classes that do not express GH146. lola $\%$ clones label many additional cells in the adPN lineage as well as IPNs and LNs (Figure 7c2). lola $\mathrm{L}^{-}$ 1- clones show similar types of mislabeling (Figure 7c3). This strongly suggests that lola function is normally necessary to repress the expression of NP3529 in multiple cell types.

Lola also appears to positively regulate gene expression. Lim1 is expressed in a subset of PNs, including most (at least four) vPNs labeled by GH146 (Figure 7d1,d2) [14]. In lola $\%$ mutant cells, Lim1 expression is lost (Figure $7 \mathrm{e} 1, \mathrm{e} 2)$. Lim 1 expression cannot be rescued by expression of either UAS-lola A or UAS-lola $T$ in lola $\%$ clones $(\mathrm{n}=2$ each for UAS-lola A and UAS-lola T; data not shown). Lim1 expression is also lost in vPNs mutant for the TF cut [14]. However, Cut expression is not altered in lola $/$-clones, and Lola expression is not altered in $\mathrm{cut}^{-}$-clones (data not shown), suggesting these TFs coordinately regulate Lim 1 expression through parallel pathways. Intriguingly, PNs mutant for lola, lim 1 or cut all fail to target DA1, suggesting that cut and lola may be necessary for regulation of other TFs as well as wiring. Antibody staining patterns of other TFs previously identified to be important for PN targeting, including acj6, drifter, cut, chip and islet, are not disrupted in lola $\%$ clones (data not shown). Taken together, these data suggest that lola can positively and negatively regulate gene expression of other genes known to label subsets of $\mathrm{PNs}$ or to play a role in PN wiring specificity.

\section{Conclusion}

Wiring specificity in Drosophila olfactory projection neurons is regulated by intrinsic TFs [13-15]. Here we have characterized an additional $\mathrm{TF}$, Lola, as necessary for proper AL wiring specificity of both PN dendrites and axons. lola $\%$ mutant clones show a wide variety of wiring phenotypes, including a loss of targeting to correct glomeruli, innervation of ectopic targets, a loss of lineage restriction in dendritic projections, a loss of AL boundary restriction, and an increase in wandering projections and ectopic branch formation. Additionally, lola appears normally to repress the expression of multiple Gal4 drivers in certain cell-types and positively regulate $\lim 1$ in vPNs. These data suggest that lola regulates multiple developmental processes, including identity as well as wiring specificity of PNs, consistent with its expression in neuroblasts and post-mitotic neurons. In fact, the wide 

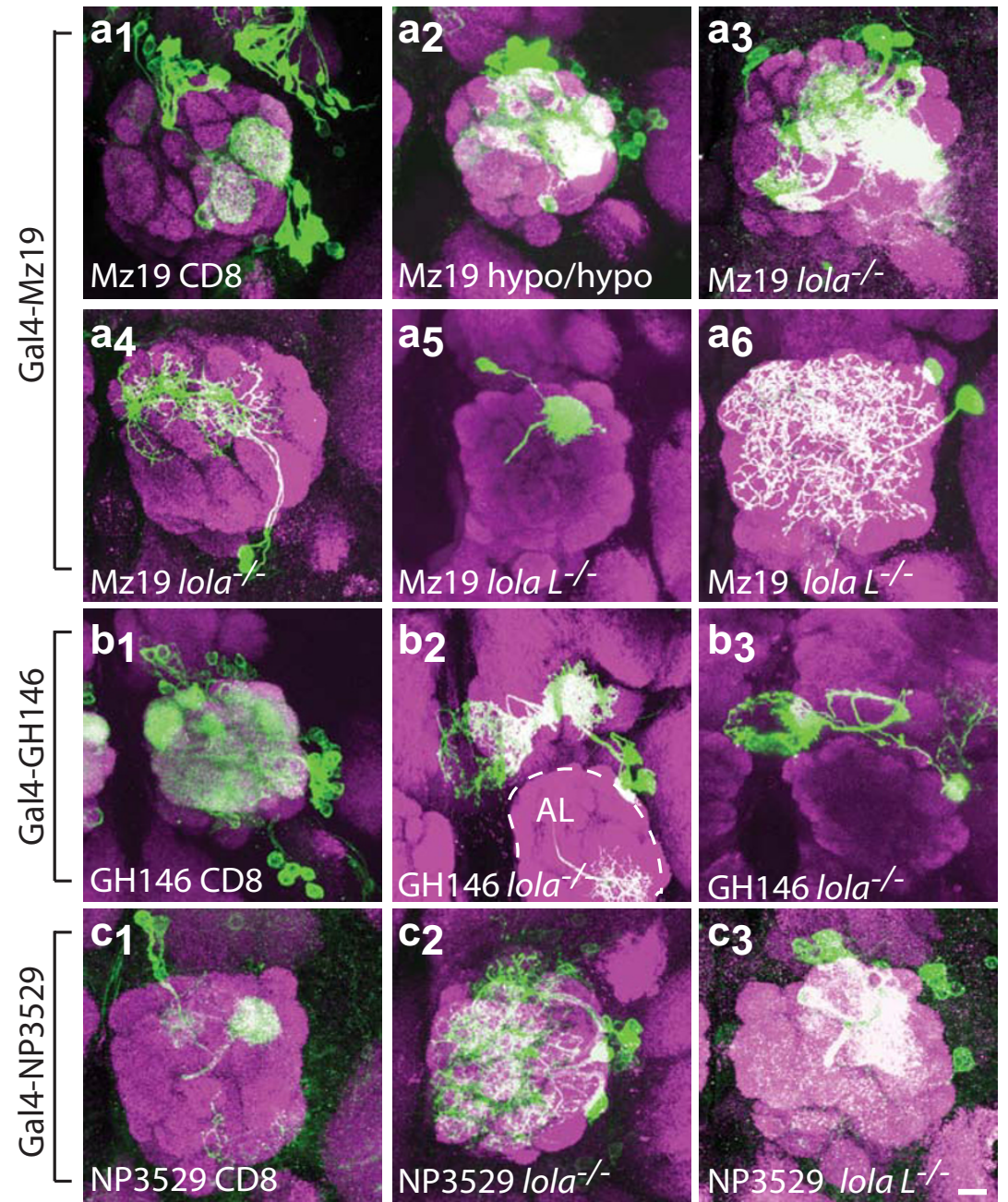



GFP lim1 DAPI

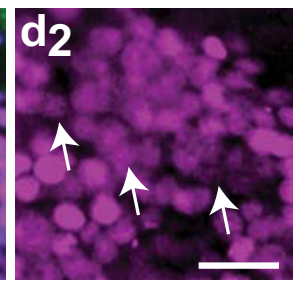

$\lim 1$

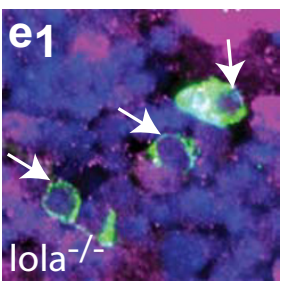

GFP lim1 DAPI

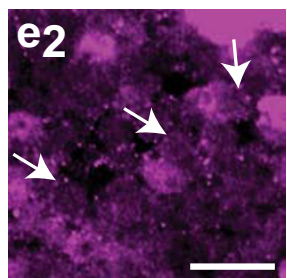

$\lim 1$

\section{Figure 7}

Evidence that lola regulates expression of Gal4 drivers and Lim I. (a) Gal4-MzI9 mislabeling analysis. Whole-animal Gal4-MzI9, UAS-GFP::CD8 expression labels a small subset of PNs $\left(a_{1}\right)$. See Figure 2 for Mzl 9 and GHI 46 MARCM controls. Mutations in Iola result in the labeling of more cell bodies than MzI9 normally labels (hypo: ore5D2) $\left(a_{2}, a_{3}\right)$, as well as the labeling of ectopic cell types such as local interneurons (LNs) $\left(a_{4}, a_{6}\right)$ and DLI that is normally labeled by Gal4-GHI46 but not Gal4-Mzl9 (a $\left.a_{5}\right)$. (b) lola- $/$ Gal4-GHI46 clones frequently mislabel a set of neurons in the region of the AL that project to the medial lobe of the MB and to the central body complex. (c) NP3529 mislabeling analysis. NP3529 labels two dorsal PNs that project to DLI (c $\left.c_{1}\right)$. lolaI- clones dramatically increase the number of cells labeled near the $A L$, including cells in the lateral lineage and $L N s\left(c_{2}\right)$. lolaL-/clones show similar mislabeling $\left(c_{3}\right)$. anti-CD8::GFP in green, anti-nc82 neuropil in magenta. (d, e) lola regulates Lim I expression in vPNs. Wild-type cells in the region of the antennal lobe, including most (at least four) vPNs express Lim I (d). In lola-/cells, Lim I expression is lost in vPNs (e). Note that the lola ${ }^{-/-}$clone includes neighboring cells in addition to those labeled by Gal4-GHI46, and many cells have lost Lim I staining. White arrows mark the cell bodies of GFP positive cells. anti-CD8::GFP in green, anti-Lim I in magenta, DAPI in blue. Scale bar, $10 \mu \mathrm{m}$. 
variety of phenotypes observed in lola mutants may be a general characteristic of genes involved in multiple developmental processes, as similar phenotypes are observed in mutants of general TF complex cofactors, such as chip [14], or are known chromatin regulatory genes (D Berdnik and LL, unpublished data). This is the first report linking roles for lola in both fate and wiring specificity in the same cell-type, suggesting that PNs have a tightly linked relationship between targeting specificity and cell identity.

lola is a highly complex genetic locus and encodes at least 20 different splice isoforms [16]. Although Lola is expressed throughout development, quantitative RT-PCR reveals that individual isoforms have different levels of expression. The diversity of lola isoform expression in PNs also appears important, as expression of a single UAS-lola transgene fails to rescue null mutant phenotypes and often results in even more severe phenotypes that are specific to the expressed lola isoform. We tested available isoform-specific lola alleles, and found that an isoform L (but not K) mutant has mild targeting defects. The difficulties of generating other isoform-specific alleles in this locus, coupled with the strong gain-of-function effect of expressing transgenes of a single isoform, made it difficult for us to investigate further isoform-specific functions of lola in PN development. However, taken together with previous reports $[16,25,16,25]$, our results support the notion that different isoforms may have unique functions in PNs in addition to embryonic motor neurons.

Several lines of evidence suggest that Lola can regulate chromatin structure. Loss of function (LOF) mutations in lola enhance the $\mathrm{Pc} /+$ phenotype and result in a significant increase in the number of sex-combs on the second leg, as do other known PcG factors [28]. This reported PcG interaction, in addition to direct binding of the chromosomal kinase JIL-1 and the presence of the nucleosome binding $\mathrm{C}_{2} \mathrm{HC}$ class $\mathrm{Zn}$-finger $[20,21]$, suggests that at least some Lola isoforms may be part of chromatin regulatory complexes. Additionally, at least one Lola isoform has been shown to bind directly to DNA and regulate expression of the copia retrotransposon [22]. Many chromatin regulators are integral components in pathways of cell fate specification. Neuronal cell fate is closely linked with dendritic and axonal targeting, particularly in PNs where cell identities based on birth order are manifested as wiring choices and target specification [2]. This link between targeting and cell identity has been suggested in the $\mathrm{MB}$, where mutation of the chromatin modifier polyhomeotic causes MB neurons to randomly express certain Hox genes that are normally suppressed and to display a wide variety of axon targeting defects that are neither a complete targeting fate switch nor consistent between individuals [32]. This is reminiscent of the lola phenotype in PNs, suggesting that lola might function in a similar manner. lola may additionally play a more direct role in targeting. lola mutants affect some glomeruli more severely than others and have post-mitotic functions in DL1 dendritic targeting, suggesting that there is a differential requirement for, or sensitivity to, the loss of lola between individual PNs. lola also has specific targeting phenotypes in the embryonic central and peripheral nervous systems, as mutations in lola seem to disrupt axon guidance and extension of the $\mathrm{Ap}^{+}$, VUM, and $\mathrm{ISN}_{\mathrm{b}}$ neurons without affecting the numbers or differentiation of these neuronal subtypes [16,24,25,29]. Taken together, this evidence suggests that lola may participate both in fate determination and, more directly, in wiring specificity. If the processes of fate determination and wiring specificity are separable, one might expect a factor that controls wiring to directly regulate the expression of genes that function in targeting, such as cell surface receptors, while a factor that controls cell fate should affect the expression of 'fate' markers that subsequently disrupt downstream expression of the components of the wiring machinery in an indirect fashion. Future identification of direct targets of lola regulation will be informative and necessary to understand the exact mechanism of lola function in PNs.

The idea that TFs can differentially control fate specification and wiring specificity is consistent with the model of a hierarchical TF code that determines wiring specificity. It is interesting to consider the possibility that some TFs may be used at multiple points during identity and wiring specification. In neuron sub-type specification in the ventral nerve cord, the TF collier specifies the precursors of the Ap neuron subset, but must be turned-off in three of the four Ap cells as subsequent participation of collier in a multi-protein complex later in development defines a unique sub-type of Ap neurons [33]. During development of the peripheral nervous system, cut specifies sensory neuron identity and is required again later in development at different levels in subpopulations of dendritic arborization neurons to specify subclass arborization [34]. Similarly, in vPN development, the TF Cut is necessary in the neuroblast for generation of the correct number of vPNs and postmitotically for specific targeting of the VA1lm glomerulus [14]. Temporal regulation and multi-functionality of TFs are possible mechanisms to limit the required number of genes in a TF code while still uniquely specifying cell identity. Lola is a potential candidate for a TF that may function in this way, both specifying cell identity and playing more specific roles later in development in regulating wiring specificity.

\section{Methods \\ Fly stocks and reagents}

MARCM stocks used were as previously published [35]. Gal4-GH146 and Gal4-Mz19 are available from the Bloomington Stock Center, and Gal4-NP3529 is from the 
Kyoto Stock Center. lolare76 (early stop codon in BTB domain predicted to be protein null for all Lola isoforms), lola ${ }^{\text {ore119 }}$ (Pro712 to Leu mutation in the Zn-finger linker region of isoform $\mathrm{L}$ predicted to reduce DNA binding by 95\%), lola ${ }^{\text {orc } 4}$ (C to T transition introduces an early stop in amino acid 771 of isoform K), lola ${ }^{5 D 2}$ (P-element insertion into the lola promoter predicted to be strongly hypomorphic allele and eliminate most lola transcription), UAS-lola A (X), UAS-lola T (X) and UAS-lola T (III) have been described previously $[16,24,25]$. We generated three new UAS-lola $L$ lines with insertions on chromosome III. The lola $L$ coding region was cloned into p [UAST] [36] and injected into embryos. Single $G_{0}$ males were crossed to yw; Pin/CyO virgins. Single $\mathrm{F}_{1}$ males with red eyes were crossed to yw; Pin/CyO virgins to establish stocks and identify the insertion chromosome.

Genotypes of flies generated in experiments are as follows: (Lola protein expression time course and Lim 1 WT staining) yw; Gal4-GH146, UAS-mCD8a::GFP (GH146 staining and LOF analyses) hsFlpCD8; FRT42D, Gal80/ FRT42D, lolax, GH146, UAS-mCD8a::GFP [where $\mathrm{x}$ denotes any lola allele] (control GH146 MARCM) hsFlpCD8; FRT42D, Gal80/FRT42D, GH146, UAS$m C D 8 a:$ GFP (lolaORC4 LOF analysis) hsFlpCD8; FRT42D, Gal80/FRT42D, lolaorc4, GH146, UAS-mCD8a::GFP (control Mz19 MARCM) hsFlpCD8; Gal4-Mz19, UAS$m C D 8 a:: G F P$, FRT42D, Gal80/FRT42D (Mz19 LOF analysis) hsFlpCD8; Gal4-Mz19, UAS-mCD8a::GFP, FRT42D, Gal80/FRT42D, lolax (UAS-lola A misexpression) UAS-lola A/hsFlp 122, UAS-mCD8a::GFP; FRT42D，Gal80/FRT42D, Gal4-GH146, UAS-mCD8a::GFP (UAS-lola L (X) misexpression) UAS-lola T/hsFlp ${ }^{122}$, UAS-mCD8a::GFP; FRT42D, Gal80/FRT42D, Gal4-GH146, UAS$m C D 8 a:$ GFP (UAS-lola $T$ (III) misexpression) hsFlp ${ }^{122,}$ UAS-mCD8a::GFP; FRT42D， Gal80/FRT42D， Gal4GH146, UAS-mCD8a::GFP; UAS-lola T (UAS-lola L misexpression) hsFlp ${ }^{122}$, UAS-mCD8a::GFP; FRT42D, Gal80/ FRT42D, Gal4-GH146, UAS-mCD8a::GFP; UAS-lola L (UAS-lola A rescue) UAS-lola A/hsFlp ${ }^{122}$, UAS$m C D 8 a:: G F P$; FRT42D, Gal80/FRT42D, lolaORE76, Gal4GH146, UAS-mCD8a::GFP (UAS-lola T rescue) UAS-lola T/ hsFlp122, UAS-mCD8a::GFP; FRT42D, Gal80/FRT42D, lolaORE76, Gal4-GH146, UAS-mCD8a::GFP (UAS-lola L rescue) hsFlp122, UAS-mCD8a::GFP; FRT42D, Gal80/ FRT42D, lolaORE76, Gal4-GH146, UAS-mCD8a::GFP; UASlola L (NP3529 LOF analysis) hsFlp ${ }^{122,}$ UAS$m C D 8 a:$ GFP;FRT42D， Gal80/FRT42D， lolax;Gal4NP3529.

\section{Clonal and phenotypic analysis}

MARCM was performed as previously described [30,35]. Clones were induced at $24 \mathrm{~h}$ APF for all Gal 4 driver lines. Brains were dissected, fixed in $4 \%$ paraformaldehyde for 20 minutes at room temperature and stained. Brains were mounted in Slow-Fade Gold or BioMedia Mounting Medium and imaged on a Zeiss LSM Meta 510 system. Zseries were captured in $1 \mu \mathrm{m}$ sections. Fluorophores were imaged using band-pass filters to remove cross-detection between channels and pseudocolored for ease of viewing. Images were processed and scored using Image J [37] or Zeiss software. Data were analyzed using FileMaker Pro and Microsoft Excel. In all, we scored 48 distinct glomeruli in the AL, based on published models [38]. Glomeruli were considered innervated when dendrites entered the nc82 stained synaptic dense region and elaborated extensions within the glomerulus (that is, a single extension passing through a glomerulus was not enough to warrant scoring as positively innervated).

\section{Antibodies and staining}

Antibody staining was performed as previously described $[14,39]$. The following primary antibodies were used; rat anti-mCD8a (Caltag [Burlingame, California, USA]), 1:100; monoclonal antibody (mAb) nc82 (developed by E Buchner and obtained from the Developmental Studies Hybridoma Bank (DSHB) [Iowa City, Iowa, USA]), 1:30; rabbit anti-Lola common region [24], 1:100; mAb antiCut (DSHB), 1:20; guinea pig anti-Lim1 (a gift from J Botas), 1:500; rat anti-Islet (a gift from J Skeath), 1:1,000; rabbit anti-Chip (a gift from D Dorsett), 1:500; mouse monoclonal anti-Acj6 [40], 1:5; rat anti-Drifter [41], 1:3,000; mouse monoclonal 7F1 anti-lola zf5 [21]. Nuclei were counterstained with DAPI $(5 \mathrm{mg} / \mathrm{ml}$ stock $1: 1,000)$.

\section{Laser-dissection microscopy and RT-PCR}

White y, w; Gal4-GH146, UAS-CD8::GFP pre-pupa (considered 0 h APF) were collected, covered with optimal cutting temperature compound (Tissue Tek O.C.T. \#4583 [Sakura Finetek, Torrance, California, USA]), frozen on dry ice and stored at $-80^{\circ} \mathrm{C}$ not longer than 1 month. Blocks were sectioned on a cryostat and sections containing ALs were mounted on PEN membrane slides (Leica $\# 11505158$ ) and stored on dry ice. Slides were put through an EtOH dehydration series (75\%, 95\%, 100\% EtOH 5 minutes each), treated for 2 minutes with xylenes, dried and mounted for LCM capture. PN enriched samples as identified by GFP fluorescence were immediately captured into PCR tube caps on a Leica LCM microscope (model ASLMD) using Laser Microdissection software version 4.4. Tubes were frozen on dry ice and stored at $-80^{\circ} \mathrm{C}$ up to one day. RNA was extracted using the Arcturus PicoPure $^{\mathrm{TM}}$ RNA Isolation kit (\#KIT0204, Mountain View, California, USA) as per the manufacturer's instructions.

The cRNA samples were used as the template for another round of reverse transcription (\#18080-051, Invitrogen [Carlsbad, California, USA]), producing a high yield of cDNA. The cDNA samples were aliquoted and stored at $20^{\circ} \mathrm{C}$ before use. Unique primer pairs and Taqman probes 
were designed for individual lola isoforms. The Taqman probes were synthesized by Integrated DNA Technologies, Inc. (Coralville, Iowa, USA). Microfluidic matrix chips (48 $\times 48$ arrays, Fluidigm (South San Francisco, California, USA) were used to perform real time PCR assays in a high throughput fashion. Each chip allows complete combinatorial tests $(48 \times 48=2,304, \mathrm{~N}=48)$ between $\mathrm{N}$ independent cDNA samples and $\mathrm{N}$ distinct primer pairs [42]. A separate paper is to be published with more technical details.

\section{In situ hybridization}

Probes for lola were designed to the common region and isoform specific exons (for primers see Table S6 in additional file 2). Isoforms are referred to based on the previously described naming scheme [16]. Probes were amplified from adult genomic preps or from embryo RNA via RT-PCR, topo-cloned and sequenced to verify identity. DIG-labeled RNA probes were generated from plasmid DNA using the Roche DIG-RNA Labeling Kit (\#11175025910, Indianapolis, Indiana, USA) following the manufacturer's protocol. Sense and antisense probes were generated from the same plasmid, taking advantage of the SP6 and T7 dual promoter flanked PCR2.1-Topo (\# K460001, Invitrogen) cloning site. Probes were diluted to $10 \mathrm{ng} / \mu \mathrm{l}$ and stored at $-80^{\circ} \mathrm{C}$ for up to 6 months. We collected $0 \mathrm{~h}$ APF pre-pupa, which were frozen in OCT on dry ice, stored at $-80^{\circ} \mathrm{C}$ not more than 1 month and sectioned on a cryostat. An in-depth protocol for in situ hybridization is available in additional file 7 . Briefly, slides were fixed in 4\% PFA for 15 minutes, washed, acetylated, washed, and pre-hybridized at room temperature. Probes were added at concentrations ranging from $5 \mathrm{ng}$ to $100 \mathrm{ng}$ and slides were incubated $18 \mathrm{~h}$ overnight at $55^{\circ} \mathrm{C}$. Slides were washed, native biotin blocked and blocked in normal goat serum. Sheep anti-DIG or rabbit anti-DIG and chicken anti-GFP primaries were added and incubated overnight at $4^{\circ} \mathrm{C}$. Slides were washed, treated with a tyramide signal amplification kit for DIG signal detection (Dako \#K0620 [Carpinteria, California, USA]), then incubated with secondary anti-chicken antibody. Slides were washed, mounted and imaged.

\section{Competing interests}

S Quake is a co-founder, consultant, and equity holder of Fluidigm Corporation. All other authors declare that they have no competing interests.

\section{Authors' contributions}

Maria Spletter designed the study, wrote the manuscript, and performed or participated in all experiments. Justin Liu participated in Lola antibody staining experiments, Gal4-GH146 driver characterization at larval time-points, and MARCM experiments. Helen Su helped develop the in situ protocol and participated in in situ hybridization experiments. Jian Liu helped conceive of and design and participated in LCM RT-PCR experiments. Stephen Quake helped conceive of and participated in the design and analysis of LCM RT-PCR experiments. Edward Giniger helped revise the manuscript and provided initial reagents and intellectual input for the study. Takaki Komiyama originally conceived of the study, performed initial PN phenotype characterization of the lola ORE5D2 allele and helped revise the manuscript. Liqun Luo participated in the overall design and coordination of the study and helped write the manuscript. All authors have read and approved the final manuscript.

\section{Additional material}

\section{Additional file 1}

Additional lola mutant allele MARCM analysis demonstrating dendritic targeting defects. Supplemental Figure S1 showing targeting defects in lolaore5D2, lolaor4, and lola ${ }^{\text {ore } 119}$ mutant PNs.

Click here for file

[http://www.biomedcentral.com/content/supplementary/17498104-2-14-S1.pdf]

\section{Additional file 2}

Supplemental Tables S1-S6. Supplemental tables and legends referenced in the main text. This includes a semi-quantitative analysis of axon targeting defects in lola $\%$ and lolaORE5D20-\%, a complete summary of DL1 dendrite and axon phenotypes by allele as percentage affected, a complete summary of $v \mathrm{PN}$ dendritic phenotypes by allele as percentage targeted correctly, clonal frequencies for MARCM experiments and primer sequences for in situ hybridization probes.

Click here for file

[http://www.biomedcentral.com/content/supplementary/17498104-2-14-S2.doc]

\section{Additional file 3}

Additional lola isoform in situ in the Drosophila brain. Supplemental Figure S2 showing controls and verification for our in situ technique and additional lola isoform hybridization results.

Click here for file

[http://www.biomedcentral.com/content/supplementary/17498104-2-14-S3.pdf]

\section{Additional file 4}

Additional lola isoform RT-PCR analysis in the Drosophila brain. Supplemental Figure S3 showing addition LCM RT-PCR experiments comparing lola isoform expression at different developmental time points and in different brain tissues.

Click here for file

[http://www.biomedcentral.com/content/supplementary/17498104-2-14-S4.pdf]

\section{Additional file 5}

Effects of UAS-lola overexpression on adPN and IPN dendrites and axons. Supplemental Figure $S 4$ showing adPN and lPN phenotypes in MARCM clones in a wild-type background expressing UAS-lola A, UASlola L and UAS-lola T.

Click here for file

[http://www.biomedcentral.com/content/supplementary/17498104-2-14-S5.pdf] 


\section{Additional file 6}

adNB and $1 N B$ phenotypes in lola $\%$, UAS-lola MARCM clones. Supplemental Figure S5 showing adPN and lPN phenotypes in lola- clones expressing UAS-lola A, UAS-lola L and UAS-lola T.

Click here for file

[http://www.biomedcentral.com/content/supplementary/1749-

8104-2-14-S6.pdf]

\section{Additional file 7}

Protocol for RNA in situ hybridization in fly larval/pupal/adult tissues. Our detailed protocol for performing RNA in situ hybridization on Drosophila at later developmental time points.

Click here for file

[http://www.biomedcentral.com/content/supplementary/17498104-2-14-S7.doc]

\section{Additional file 8}

Legends for supplemental Figures S1-S5. All supplemental figure titles and legends.

Click here for file

[http://www.biomedcentral.com/content/supplementary/1749-

8104-2-14-S8.doc]

\section{Acknowledgements}

We thank all members of the Luo lab for useful discussion and insights on this project. In particular, we thank Y Chou, E Hoopfer, O Schuldiner, JWu, C Potter, B Tasic and D Berdnik for comments on the manuscript and $O$ Schuldiner and $E$ Hoopfer for contributions to the in situ protocol. We thank the Stanford Dermatology Laser-Capture Microsopy facility for use of their LCM system; D Luginbuhl for embryo injections to generate the UAS-lola L flies; and E Lane Davies and M Fuller for kindly sharing reagents and insights on the function of lola in other tissues. Antibodies were generously provided by E Buchne, J Botas, D Dorsett, J Skeath and K Johansen. This work was supported by NIH grants to LL. MS is supported by an NIHNRSA. LL and SQ are investigators of the Howard Hughes Medical Institute.

\section{References}

I. Dickson BJ: Molecular mechanisms of axon guidance. Science 2002, 298(5600): 1959-1964.

2. Jefferis GS, Marin EC, Stocker RF, Luo L: Target neuron prespecification in the olfactory map of Drosophila. Nature 200I, 4| 4(6860):204-208.

3. Mumm JS, Williams PR, Godinho L, Koerber A, Pittman AJ, Roeser T, Chien $\mathrm{CB}$, Baier $\mathrm{H}$, Wong $\mathrm{RO}$ : In vivo imaging reveals dendritic targeting of laminated afferents by zebrafish retinal ganglion cells. Neuron 2006, 52(4):609-62I.

4. Jefferis GS, Vyas RM, Berdnik D, Ramaekers A, Stocker RF, Tanaka NK, Ito K, Luo L: Developmental origin of wiring specificity in the olfactory system of Drosophila. Development 2004, I3I(I): $117-130$.

5. Komiyama T, Luo L: Development of wiring specificity in the olfactory system. Curr Opin Neurobiol 2006, I6(I):67-73.

6. Jefferis GS, Hummel T: Wiring specificity in the olfactory system. Semin Cell Dev Biol 2006, I 7(I):50-65.

7. Marin EC, Jefferis GS, Komiyama T, Zhu H, Luo L: Representation of the glomerular olfactory map in the Drosophila brain. Cell 2002, 109(2):243-255.

8. Wong AM, Wang JW, Axel R: Spatial representation of the glomerular map in the Drosophila protocerebrum. Cell 2002, 109(2):229-24I.

9. Jefferis GSXE, Potter CJ, Chan AM, Marin EC, Rohlfing T, Maurer JCR, Luo L: Comprehensive Maps of Drosophila Higher Olfactory
Centers: Spatially Segregated Fruit and Pheromone Representation. Cell 2007, I 28(6): I I87-I 203.

10. Zhu H, Hummel T, Clemens JC, Berdnik D, Zipursky SL, Luo L: Dendritic patterning by Dscam and synaptic partner matching in the Drosophila antennal lobe. Nat Neurosci 2006, 9(3):349-355.

II. Zhu H, Luo L: Diverse functions of $\mathbf{N}$-cadherin in dendritic and axonal terminal arborization of olfactory projection neurons. Neuron 2004, 42(I):63-75.

12. Komiyama T, Sweeney LB, Schuldiner O, Garcia KC, Luo L: Graded expression of semaphorin-I a cell-autonomously directs dendritic targeting of olfactory projection neurons. Cell 2007, I 28(2):399-410.

13. Komiyama T, Johnson WA, Luo L, Jefferis GS: From lineage to wiring specificity. POU domain transcription factors control precise connections of Drosophila olfactory projection neurons. Cell 2003, II 2(2): I57-167.

14. Komiyama T, Luo L: Intrinsic control of precise dendritic targeting by an ensemble of transcription factors. Curr Biol 2007, i 7(3):278-285.

15. Zhu S, Lin S, Kao CF, Awasaki T, Chiang AS, Lee T: Gradients of the Drosophila Chinmo BTB-zinc finger protein govern neuronal temporal identity. Cell 2006, I27(2):409-422.

16. Goeke S, Greene EA, Grant PK, Gates MA, Crowner D, Aigaki T, Giniger E: Alternative splicing of lola generates 19 transcription factors controlling axon guidance in Drosophila. Nat Neurosci 2003, 6(9):917-924.

17. Horiuchi T, Giniger E, Aigaki T: Alternative trans-splicing of constant and variable exons of a Drosophila axon guidance gene, lola. Genes Dev 2003, I 7(20):2496-250I.

18. Ohsako T, Horiuchi T, Matsuo T, Komaya S, Aigaki T: Drosophila lola encodes a family of BTB-transcription regulators with highly variable C-terminal domains containing zinc finger motifs. Gene 2003, 31 1:59-69.

19. Kelly KF, Daniel JM: POZ for effect--POZ-ZF transcription factors in cancer and development. Trends Cell Biol 2006, 16(I I):578-587.

20. Akhtar A, Becker PB: The histone $\mathbf{H 4}$ acetyltransferase MOF uses a C2HC zinc finger for substrate recognition. EMBO Rep 2001, 2(2): I| $13-118$.

21. Zhang W, Wang Y, Long J, Girton J, Johansen J, Johansen KM: A developmentally regulated splice variant from the complex lola locus encoding multiple different zinc finger domain proteins interacts with the chromosomal kinase JIL-I. J Biol Chem 2003, 278(13): I I696-II704.

22. Cavarec L, Jensen S, Casella JF, Cristescu SA, Heidmann T: Molecular cloning and characterization of a transcription factor for the copia retrotransposon with homology to the BTB-containing lola neurogenic factor. Mol Cell Biol 1997, I 7(I):482-494.

23. Giot L, Bader JS, Brouwer C, Chaudhuri A, Kuang B, Li Y, Hao YL, Ooi CE, Godwin B, Vitols E, Vijayadamodar G, Pochart P, Machineni $\mathrm{H}$, Welsh M, Kong Y, Zerhusen B, Malcolm R, Varrone Z, Collis A, Minto M, Burgess S, McDaniel L, Stimpson E, Spriggs F, Williams J, Neurath K, loime N, Agee M, Voss E, Furtak K, Renzulli R, Aanensen N, Carrolla S, Bickelhaupt E, Lazovatsky Y, DaSilva A, Zhong J, Stanyon CA, Finley RL Jr., White KP, Braverman M, Jarvie T, Gold S, Leach M, Knight J, Shimkets RA, McKenna MP, Chant J, Rothberg JM: A protein interaction map of Drosophila melanogaster. Science 2003, 302(565I): 1727-1736.

24. Giniger $E$, Tietje $K$, Jan LY, Jan YN: lola encodes a putative transcription factor required for axon growth and guidance in Drosophila. Development 1994, I 20(6): | 385- 1398.

25. Madden K, Crowner D, Giniger E: LOLA has the properties of a master regulator of axon-target interaction for $\mathrm{SNb}$ motor axons of Drosophila. Dev Biol 1999, 213(2):30I-3I3.

26. Zhang D, Zhou W, Yin C, Chen W, Ozawa R, Ang LH, Anandan L, Aigaki T, Hing H: Misexpression screen for genes altering the olfactory map in Drosophila. Genesis 2006, 44(4): I89-20I.

27. Crowner D, Madden K, Goeke S, Giniger E: Lola regulates midline crossing of CNS axons in Drosophila. Development 2002, I29(6): I3|7-1325.

28. Ferres-Marco D, Gutierrez-Garcia I, Vallejo DM, Bolivar J, GutierrezAvino FJ, Dominguez M: Epigenetic silencers and Notch collaborate to promote malignant tumours by Rb silencing. Nature 2006, 439(7075):430-436. 
29. Krupp JJ, Yaich LE, Wessells RJ, Bodmer R: Identification of genetic loci that interact with cut during Drosophila wingmargin development. Genetics 2005, I70(4): 1775-1795.

30. Lee T, Luo L: Mosaic analysis with a repressible cell marker for studies of gene function in neuronal morphogenesis. Neuron 1999, 22(3):45I-46I.

31. Kuzin A, Brody T, Moore AW, Odenwald WF: Nerfin-I is required for early axon guidance decisions in the developing Drosophila CNS. Dev Biol 2005, 277(2):347-365.

32. Wang J, Lee $\mathrm{CH}$, Lin S, Lee $\mathrm{T}$ : Steroid hormone-dependent transformation of polyhomeotic mutant neurons in the Drosophila brain. Development 2006, I33(7):|23|-1240.

33. Baumgardt M, Miguel-Aliaga I, Karlsson D, Ekman H, Thor S: Specification of neuronal identities by feedforward combinatorial coding. PLoS Biol 2007, 5(2):e37.

34. Grueber WB, Jan LY, Jan YN: Different levels of the homeodomain protein cut regulate distinct dendrite branching patterns of Drosophila multidendritic neurons. Cell 2003, I I 2(6):805-818.

35. Wu JS, Luo L: A protocol for mosaic analysis with a repressible cell marker (MARCM) in Drosophila. In Nature Protocols Volume I. Nature; 2006:2583-2589.

36. Brand $\mathrm{AH}$, Perrimon $\mathrm{N}$ : Targeted gene expression as a means of altering cell fates and generating dominant phenotypes. Development 1993, II 8(2):40|-4I5.

37. Wayne Rasband NIH USA: Image J. version I.37 [http://rsb.info.nih.gov/ij/].

38. Laissue PP, Reiter C, Hiesinger PR, Halter S, Fischbach KF, Stocker RF: Three-dimensional reconstruction of the antennal lobe in Drosophila melanogaster. J Comp Neurol 1999, 405(4):543-552.

39. Wu JS, Luo L: A protocol for dissecting Drosophila melanogaster brains for live imaging or immunostaining. Nature Protocols 2006, I:2110-2115.

40. Certel SJ, Clyne PJ, Carlson JR, Johnson WA: Regulation of central neuron synaptic targeting by the Drosophila POU protein, Acj6. Development 2000, I 27(II):2395-2405.

4I. Anderson MG, Perkins GL, Chittick P, Shrigley RJ, Johnson WA: drifter, a Drosophila POU-domain transcription factor, is required for correct differentiation and migration of tracheal cells and midline glia. Genes Dev 1995, 9(I): 123-137.

42. Liu J, Hansen C, Quake SR: Solving the "world-to-chip" interface problem with a microfluidic matrix. Anal Chem 2003, 75(18):47|8-4723.

Publish with Bio Med Central and every scientist can read your work free of charge

"BioMed Central will be the most significant development for disseminating the results of biomedical research in our lifetime. "

Sir Paul Nurse, Cancer Research UK

Your research papers will be:

- available free of charge to the entire biomedical community

- peer reviewed and published immediately upon acceptance

- cited in PubMed and archived on PubMed Central

- yours - you keep the copyright
BioMedcentral 